\title{
Analysis of the surface temperature and wind forecast errors of the NCAR-AirDat operational CONUS 4-km WRF forecasting system
}

\author{
Andrzej A. Wyszogrodzki - Yubao Liu • \\ Neil Jacobs $\cdot$ Peter Childs $\cdot$ Yongxin Zhang $\cdot$ \\ Gregory Roux $\cdot$ Thomas T. Warner
}

Received: 15 February 2013/Accepted: 3 September 2013/Published online: 20 September 2013

(C) The Author(s) 2013. This article is published with open access at Springerlink.com

\begin{abstract}
Investigating the characteristics of modelforecast errors using various statistical and object-oriented methods is necessary for providing useful guidance to endusers and model developers as well. To this end, the random and systematic errors (i.e., biases) of the 2-m temperature and $10-\mathrm{m}$ wind predictions of the NCAR-AirDat weather research and forecasting (WRF)-based real-time four-dimensional data assimilation (RTFDDA) and forecasting system are analyzed. This system has been running operationally over a contiguous United States (CONUS) domain at a 4-km grid spacing with four forecast cycles daily from June 2009 to September 2010. In the result an exceptionally useful forecast dataset was generated and used for studying the error properties of the model forecasts, in terms of both a longer time period and a broader coverage of geographic regions than previously studied. Spatiotemporal characteristics of the errors are investigated based on the 24-h forecasts between June 2009 and April 2010, and the 72-h forecasts between May and September 2010. It was found that the biases of both wind and temperature forecasts vary greatly seasonally and diurnally,
\end{abstract}

Responsible editor: J.-F. Miao.

A. A. Wyszogrodzki (凹) · Y. Liu · Y. Zhang · G. Roux ·

T. T. Warner

Research Applications Laboratory, National Center for

Atmospheric Research, PO Box 3000, Boulder,

CO 80307-3000, USA

e-mail: andii@ucar.edu

N. Jacobs $\cdot$ P. Childs

Airdat LLC, Morrisville, NC, USA

T. T. Warner

Department of Atmospheric and Oceanic Sciences,

University of Colorado, Boulder, CO, USA with dependency on the forecast length, station elevation, geographical location, and meteorological conditions. The temperature showed systematic cold biases during the daytime at all station elevations and warm biases during the nighttime above $1,000 \mathrm{~m}$ above sea level (ASL), while below $600 \mathrm{~m}$ ASL cold biases occurred during the nighttime. The forecasts of surface wind speed exhibited strong positive biases during the nighttime, while the negative biases were observed in the spring and summer afternoons. The surface wind speed was mostly over-predicted except for the stations located between 1,000 and 2,100 m ASL, for which negative biases were identified for most forecast cycles. The highest wind-speed errors were found over the high terrain and near sea-level stations. The wind-direction errors were relatively large at the high-terrain elevation in the Rocky and Appalachian mountain ranges and the western coastal areas and the error structure exhibited notable diurnal variability.

\section{Introduction}

Mesoscale numerical weather prediction (NWP) models driven by global model output provide valuable short-term weather forecasts at regional scales with refined model grids and customized model physics. Increases in model resolution have made it possible to realistically resolve the interaction of large-scale circulations with local terrain, thus providing more accurate representation of local wind, convection, and precipitation. The growing desire for more accurate weather forecasts has led to steady improvements in the operational NWP models. Despite the improvements, model forecasting is inherently affected by imperfect initial and boundary conditions, numerical approximations of the dynamical equations (e.g., truncation errors), and 
simplifications of the complex atmospheric physical and chemical processes. As a result, NWP model forecasts are inevitably subject to systematic (biases) and random errors (Cheng and Steenburgh 2005; Molders 2008; Liu et al. 2009; Coleman et al. 2010). Investigating the characteristics of model-forecast errors using various statistical and object-oriented methods is instrumental in providing useful guidance to end-users and model developers as well.

Analysis of model-forecast errors, especially the systematic biases, is the first step for model developers to understand the model behavior and develop a solution to reduce the model errors. Such statistical error features can help model developers identify the limitations and make improvements to model resolution, physics parameterizations, assimilating higher density data, and more accurate model numerics. For example, high-resolution models are able to realistically resolve many of the mesoscale features that arise from the interaction of large-scale flow with topography (Fritsch et al. 1998), where a myriad of mesoscale processes have been recognized as significant sources of errors for models (Rife et al. 2002, 2004). A few studies (e.g., Hahn and Mass 2009; Lin and Colle 2009) have also shown that the use of the positive-definite advection (PDA) algorithms reduces spuriously generated moisture at high-model resolutions.

Forecasts of surface- and boundary-layer variables rely heavily on surface conditions including soil temperature and moisture (Chen et al. 2001; Holt et al. 2006; Sutton et al. 2006), properties of land surface (land use, land cover, vegetation; Barlage et al. 2010), and the coupling between such parameters within the land-surface model (LSM) and PBL parameterizations (Liu et al. 2006). The model microphysics and radiation may represent additional sources of biases in temperature and precipitation. Improvements in bulk microphysical parameterizations introduced in MM5 (Woods et al. 2007) and WRF (Lin and Colle 2011) not only produce better snow forecasts, but also reduce some biases in surface temperature. The deficiencies in cloud microphysics, boundary-layer parameterizations and surface physics, might have also contribute to the overprediction of precipitation near complex orography (Hahn and Mass 2009). Several recent studies attempt to correct wind biases by accounting for the unresolved topographic features. Mass and Ovens (2011) showed that by using surface roughness length proportional to the magnitude of sub-grid scale terrain variance, both wind-speed and winddirection bias could be greatly reduced. More recently, Jiménez and Dudhia (2012) added a new surface sink term in the WRF momentum equation to take into account the effects of the unresolved terrain, which improved climatological and intra-diurnal wind speed variability.

Data assimilation presents another means to reduce model biases by improving the quality of initial conditions.
By taking advantage of the new observational technologies and advanced data assimilation techniques, e.g., an off-line high-resolution land-surface model (LSM) spun-up (Case et al. 2008), or the initialization of the model through assimilation of diverse observations, such as satellite radiance data (Xu et al. 2009), or tropospheric airborne meteorological data reporting (TAMDAR) measurements (Childs 2010), the model-forecast errors could be further mitigated.

Over the last 3 years, NCAR and AirDat LLC have jointly developed a real-time operational WRF-based realtime four-dimensional data assimilation (WRF-RTFDDA) forecasting system that covers the contiguous US (CONUS) with two nested-grid domains at 12- and 4-km grid intervals, respectively (Fig. 1). This system has been running in a real-time operational mode since July 2009. One significant component of the WRF-RTFDDA system is a data assimilation component that continuously assimilates meteorological observations as they become available, enabling the system to generate model-assimilated and model-adjusted datasets that both define the current atmospheric conditions and serve as the initial conditions for subsequent model forecasts (Liu et al. 2008a). This high-resolution CONUS-scale system provides an exceptionally useful forecast dataset for studying the error properties of the WRF model forecasts, in terms of a longer time period and a broader coverage of geographic regions than previously studied. In this paper, we examine the temporal and spatial error characteristics of the forecasts as a function of station elevations, geographical locations across CONUS, seasonal migration, and meteorological conditions. We compute and characterize the statistical properties of the surface wind and temperature forecast biases and root-mean squared errors (RMSEs) of this real-

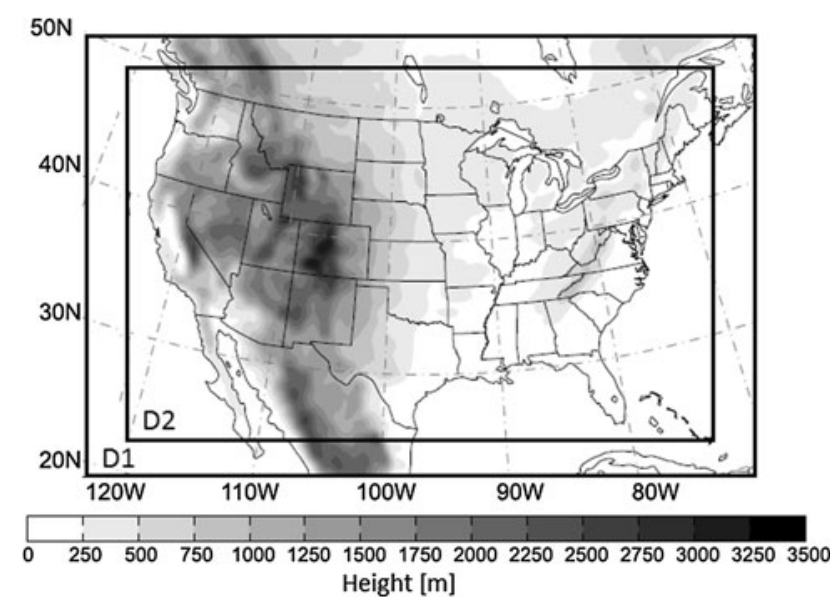

Fig. 1 Model domains and terrain height (shading). The external domain, D1, consists of $441 \times 303 \times 36$ grid points at a $12-\mathrm{km}$ grid spacing; the internal domain, D2, contains $1,192 \times 766 \times 36$ grid points at a $4-\mathrm{km}$ grid spacing 
time operational high-resolution 4-km WRF-RTFDDA system.

This paper is organized as follows. Section 2 describes the modeling system, data archive, and the bias verification methods. The spatiotemporal structures of the model biases are analyzed and discussed in Sect. 3. Section 4 examines the bias geographical distributions and their dependency on the terrain height. Summary and discussions are provided in Sect. 5.

\section{Description of the operational system and verification methodology}

WRF-RTFDDA is one of the real-time operational data assimilation and forecasting systems developed by NCAR, and has been implemented over various regions to support many applications and provide multi-scale weather analyses and forecasts with fine-mesh domains down to a grid spacing of 0.5-3 km (Liu et al. 2008a, b; Sharman et al. 2008). The core of the forecasting system is the Advanced Research WRF (ARW; Skamarock et al. 2005) modeling framework. This system continuously assimilates all synoptic and asynoptic weather observations using observation nudging based on Newtonian relaxation (Liu et al. 2007). The use of multi-scale domains and rapid cycling produces dynamically spun-up and physically consistent initial conditions for short-term mesoscale weather forecasts (Liu et al. 2006, 2008a).

\subsection{NCAR-AirDat WRF-RTFDDA system}

The operational WRF-RTFDDA was deployed at AirDat for real-time forecasts over a CONUS domain in July 2009 (Liu et al. 2010). The system was set up with two one-waynested domains (Fig. 1), which was found to be a computationally efficient configuration due to the reduction of the cost of the WRF preprocessing computations through the use of a 12-km coarse grid. The external domain (D1) consists of $441 \times 303$ points at a $12-\mathrm{km}$ horizontal grid spacing, and the internal domain (D2) has $1,192 \times 766$ grid points at a 4-km horizontal grid spacing, both domains employing 37 vertical levels in the entire layer with 13 levels located between the surface and the $1.5-\mathrm{km}$ height. The lowest model level is about $10 \mathrm{~m}$ above the surface. For both domains, 27 modified USGS land-use categories and 19 soil categories are used. Table 1 shows the physical parameterization schemes employed by this system. In December 2009, the microphysics scheme was switched from the Lin et al. (1983) scheme to the more sophisticated Morrison two-moment scheme (i.e., Morrison et al. 2009), which predicts the mixing ratios of rain, ice, snow, and graupel, as well as their number concentrations. The system has been running four forecast cycles per day starting at 00, 06, 12, and 18 UTC. Each cycle produces a 6-h analysis through continuous data assimilation and 72-h forecasts (24-h forecasts before 22 April, 2010). In the NCAR-AirDat WRF-RTFDDA system, the PDA algorithm is applied for both the 12- and 4-km grids. The system cold starts once a week on Saturdays at $18 \mathrm{Z}$.

\subsection{Forecast data sets}

Observation nudging is used in the WRF-RTFDDA for continuously collecting and ingesting all available synoptic and asynoptic weather observations from conventional and unconventional platforms, e.g., various surface data (METAR, SYNOP, SPECI, ship, buoy, QuikScat seawinds, mesonets, etc.) and upper-air observations (TEMP, PILOT, wind profilers, aircrafts, satellite winds, dropsondes, radiometer profilers, RAOBS, Doppler radar winds, and others). Multi-stage cycling allows for the ingestion of data with different time lags to provide continuous analyses and forecasts at a specified time interval-in this case, $3 \mathrm{~h}$.

The real-time verification statistics analyzed in this paper were generated using the forecasts over a period of 14 months, with 24-h forecasts from 1 July, 2009 through 22 April, 2010 (hereafter denoted as S1), and 72-h forecasts from 22 May, 2010 through 9 September, 2010. Figure 2 shows examples of the typical weather regimes during the cool (S1) and warm (S2) seasons. The S1 period is characterized in a large part by the passage of frontal systems during the winter and spring seasons, while the S2 period is characterized by convective activities during the summer and early fall.

Finally, it is noted here that one of the unique datasets assimilated in the NCAR-AirDat WRF-RTFDDA system is the AirDat TAMDAR observation. TAMDAR is an airborne multi-function in situ atmospheric sensor equipped on commercial aircrafts, and provides measurements of humidity, pressure, temperature, winds, icing, and

Table 1 List of NCAR-AirDat WRF-RTFDDA model physical parameterization and configuration

\begin{tabular}{ll}
\hline Physics & Scheme \\
\hline Nested-grid & One-way \\
Time integration & Adaptive time step \\
Land surface & Noah \\
Surface layer & Monin-Obukhov \\
PBL & YSU (non-local mixing) \\
SW-RAD & Dudhia \\
LW-RAD & RRTM \\
Clod microphysics & Lin et at.; Morrison (from December 17, 2009) \\
Cumulus scheme & Kain-Fritsch (12 km only) \\
\hline
\end{tabular}


Fig. 2 Satellite photographs of the cloud top IR brightness temperature $\left({ }^{\circ} \mathrm{C}\right)$, during different weather regimes in $\mathrm{S} 1$ and S2: strong springtime convective systems in April 22-25 (upper panel); fairweather summer-time cumulus convection in July 6-9 (lower panel)
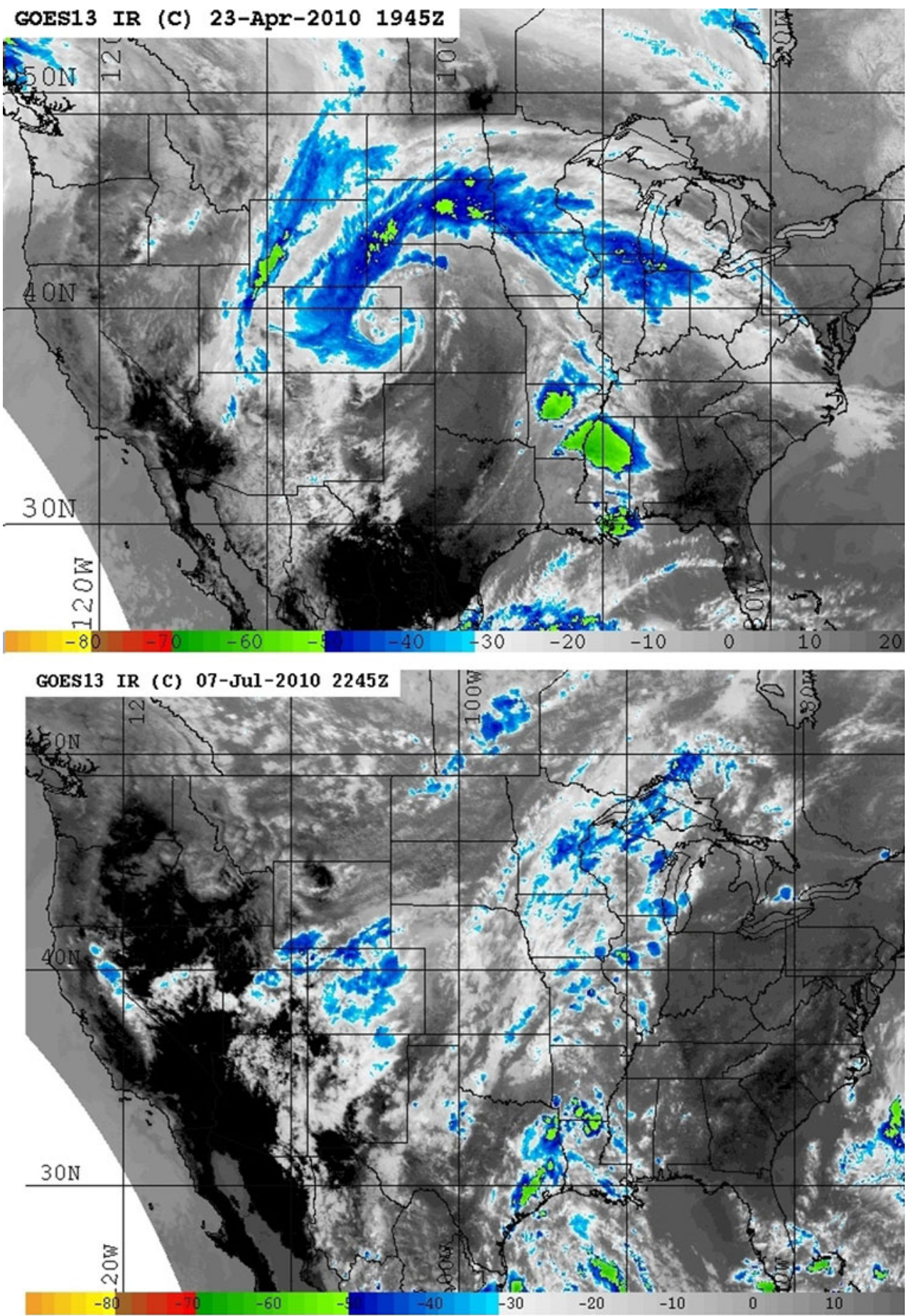

turbulence, along the flight paths. The TAMDAR sensors have been installed and operating over CONUS, Alaska, and Mexico on the Horizon, Republic, Chautauqua, Shuttle America, PenAir, Piedmont, Frontier Alaska, AeroMexico Connect and Mesaba Airlines, as well as on a few research aircrafts. Upon completion of the 2011 installations, more than 6,000 daily soundings have been produced in North America at more than 360 locations.

\subsection{Methodology of systematic error analysis}

Verification statistics of the operational forecasts are computed by interpolating WRF output (linear interpolation in horizontal and vertical directions) to observation points of all selected 523 METAR and other standard surface stations. At every forecast hour (separately in each cycle), we calculate bias and RMSE as follows: 
$\mathrm{BIAS}=1 / N \sum_{i=1}^{N}\left(C_{\mathrm{f}}(i)-C_{\mathrm{O}}(i)\right)$

$\mathrm{RMSE}=\sqrt{1 / N \sum_{i=1}^{N}\left(C_{\mathrm{f}}(i)-C_{\mathrm{O}}(i)\right)^{2}}$,

wherein $N$ is the number of all valid observations, $C_{\mathrm{O}}$ is the observed meteorological quantity at a station location and at a particular time, and $C_{\mathrm{f}}$ is the model prediction at the same time interpolated to the same location. The bias is defined here as the "difference of the central location of the forecasts and the observations" (Jolliffe and Stephenson 2011). The RMSE is generally more sensitive to large errors because the square power provides more weight to the larger error values. On the other hand, the mean bias does not reflect positive and negative errors for individual cases because they tend to cancel out. The standard deviations of the BIAS (STD BIAS $_{\text {) and RMSE (STD }}$ RMSE) as well as correlation skill score COR are also computed as

$\operatorname{STD}_{\text {BIAS }}=\sqrt{1 /(N-1) \sum_{i=1}^{N}\left(C_{\mathrm{f}}(i)-C_{\mathrm{O}}(i)-\mathrm{BIAS}\right)^{2}}$

$\operatorname{STD}_{\mathrm{RMSE}}=\sqrt{1 /(N-1) \sum_{i=1}^{N}\left(C_{\mathrm{f}}(i)-C_{\mathrm{O}}(i)-\mathrm{RMSE}\right)^{2}}$

$\operatorname{CORR}=\operatorname{cov}\left(C_{\mathrm{f}}, C_{\mathrm{O}}\right) / \sqrt{\operatorname{var}\left(C_{\mathrm{f}}\right) \operatorname{var}\left(C_{\mathrm{O}}\right)}$

The correlation skill score (CORR) evaluates systematic relations between forecasts and observations, for example, their error differences and the amplitudes. Thus, perfect correlation exists for $\mathrm{COR}=1$ or $\mathrm{COR}=-1$. $\mathrm{STD}_{\mathrm{BIAS}}$ indicates the variability of random errors relative to the bias, similarly, $\mathrm{STD}_{\mathrm{RMS}}$ to the mean RMSE.

\section{Spatiotemporal variations of the forecast biases}

The investigation of model biases and their characteristics have been the subject of several recent publications. For example, Cheng and Steenburgh (2005) and Molders (2008) showed a general tendency of the WRF model (Skamarock et al. 2005) to overestimate the $10-\mathrm{m}$ wind speed over the western part of US and Alaska, respectively. The largemagnitude bias in wind speed and wind direction was also identified in recent versions of WRF in simulations over mountainous areas (Roux et al. 2009; Mass and Ovens 2011; Jiménez and Dudhia 2012,2013). The studies of Prabha and Hoogenboom (2008) and Liu et al. (2009) reported the underestimation of the 2-m daytime temperature, with average cold biases between -4 and $-2{ }^{\circ} \mathrm{C}$. In contrast, daytime warm biases were noted by Coleman et al. (2010) in their summertime simulations over the Los Angeles basin using the WRF model, as well as the fifth-generation Pennsylvania State University-NCAR Mesoscale Model (MM5; Grell et al. 1994). Coleman et al. (2010) attributed the daytime warm biases to insufficient representation of the anthropogenic latent heat flux, a source of enthalpy, resulting in significant cooling in the planetary boundary-layer (PBL) schemes. More recently, in the springtime-2011 15- and 3-km WRF-CONUS simulations Romine et al. (2013) reported the diurnal and synoptic-scale variability in the temperature mean errors, positive bias in 2-m dewpoint, and wind-direction errors related to the synoptic variability within the model domain. In this section, we analyze the forecast errors of the 2-m temperatures and 10-m winds of the NCAR-AirDat 4-km WRF-RTFDDA system for an operational period of 14 months. All available forecast cycles during the period are included in the study.

\subsection{Domain-averaged error characteristics}

Figure 3 illustrates the domain-averaged RMSE and standard deviation of the $24 \mathrm{~h}$ forecasts of 2-m temperature, $10-\mathrm{m}$ wind speed and wind direction for the four forecast cycles $(00,06,12,18$ UTC) averaged over the entire S1 period. The averaging is done for all available forecast cycles between 1 July, 2009 and 22 April, 2010. The temperature errors exhibit strong diurnal patterns in each cycle with a growing trend during the daytime and peaking in the late afternoon. There is a period of approximately $3 \mathrm{~h}$ following the late afternoon peak when the temperature error decreases, and then stays roughly constant during the nighttime. The standard deviation of the RMSE around the mean values is moderate and never exceeds $0.4 \mathrm{~K}$ for temperature and $0.3 \mathrm{~m} \mathrm{~s}^{-1}$ for wind speed. On average, the temperature errors for the 00 UTC cycle are lower than those of the other cycles, which may be attributable to the assimilation of more aircraft data of the daytime flights and RAOB data, as noted by Croke et al. (2010). The minimum error of $1.8 \mathrm{~K}$ is always found at the end of the analysis time (or the 0 -h forecast lead time) for all the cycles, which is most likely due to the effect of continuous assimilation. The maximum error in 2-m temperature reaches $2.5 \mathrm{~K}$. Roux et al. (2009) also showed a strong effect of the diurnal cycle on the model-forecast bias, with maximum temperature errors increasing from $1.8 \mathrm{~K}$ during the analysis period to $2.5 \mathrm{~K}$ at the late afternoon hours.

In comparison, the diurnal variability in $10-\mathrm{m}$ wind speed error and 10-m wind-direction error are less pronounced when compared to those of 2-m temperature (Fig. 3). For wind speed, nighttime and early morning correspond to relatively smaller errors while relatively 
RMSE averaged between 20090701-20100422
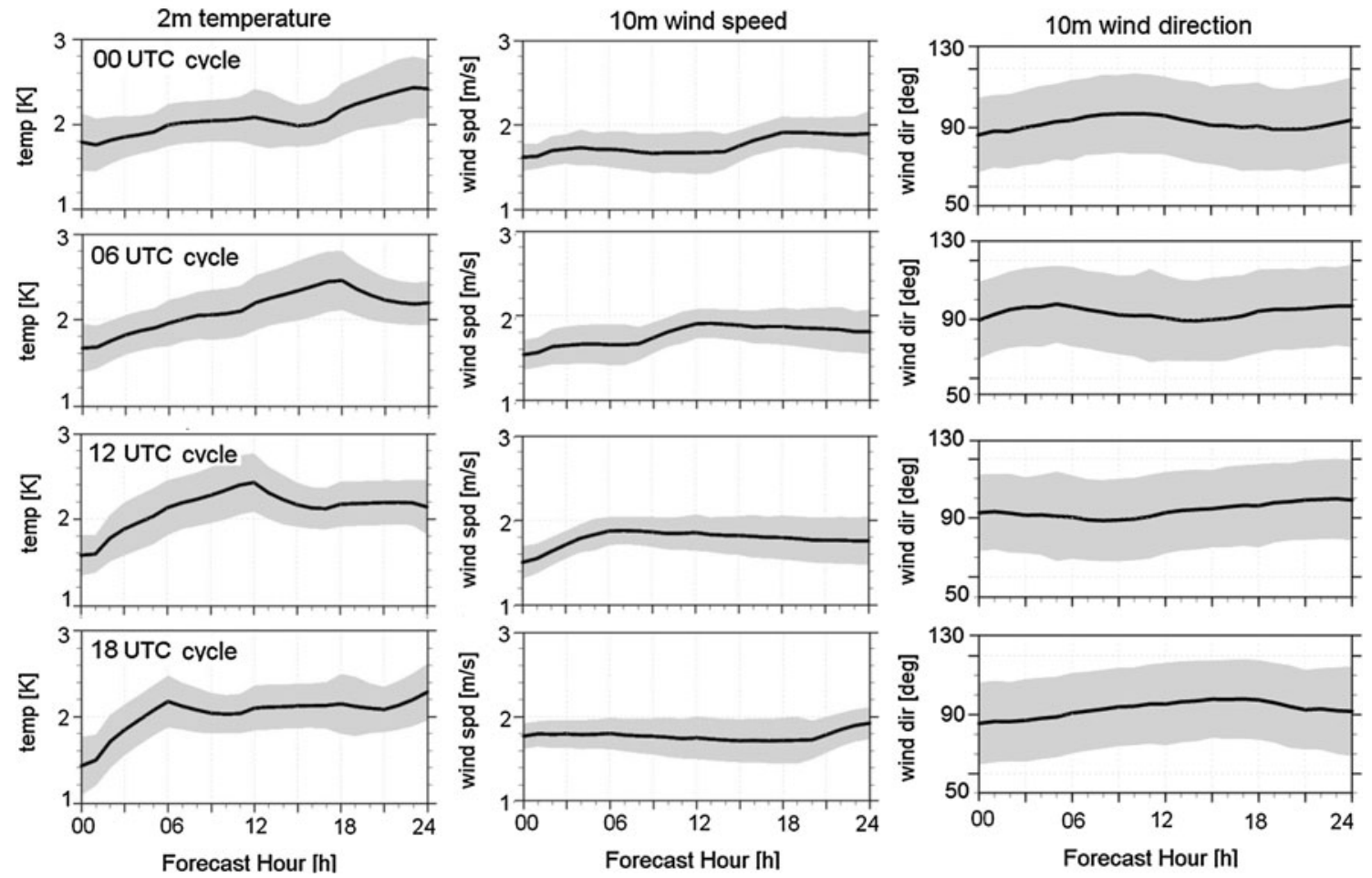

Fig. 3 Domain-averaged RMSE (black lines) and standard deviation (shadings) of 2-m temperature, 10-m wind speed, and wind-direction forecasts as a function of 0 - to 24 -h forecast lead time for each of the

larger errors on the order of $1.9 \mathrm{~m} \mathrm{~s}^{-1}$ are found around noon. For wind direction, the error distributions appear to be out of phase with those of wind speed. The spread of the RMSE around the mean is small for wind speed $\left(<0.3 \mathrm{~m} \mathrm{~s}^{-1}\right)$, but is quite large for wind direction $\left(\sim 50^{\circ}\right)$.

Figure 4 presents the domain-averaged RMSE as a function of 0 to 72 -h forecast lead time averaged over the entire S2 period. Increasing trends in the RMSEs of temperature, wind speed, and wind direction with forecast lead time are evident (especially for temperature), with superposed strong diurnal variations. The maximum temperature errors that peak in late afternoon grow from $2.5 \mathrm{~K}$ in the beginning of the forecast cycle to $3.2 \mathrm{~K}$ at the end of the forecast cycle. As in the $\mathrm{S} 1$ period, the largest wind-speed errors occur around noon, and grow from 1.9 to $2.1 \mathrm{~m} \mathrm{~s}^{-1}$ during the $72-\mathrm{h}$ forecast length. Averaged over the entire CONUS domain, the $10-\mathrm{m}$ wind-speed daytime bias is about $0.5 \mathrm{~m} \mathrm{~s}^{-1}$ while the MAE of $10-\mathrm{m}$ wind speeds grows gradually from approximately $1.2 \mathrm{~m} \mathrm{~s}^{-1}$ during the analysis period to $2 \mathrm{~m} \mathrm{~s}^{-1}$ at the end of the 72-h forecast length (not shown).

Compared to the findings of the other regional models reported in literatures, the NCAR-AirDat CONUS WRFRTFDDA system shows slightly better forecast verification statistics. Case et al. (2002) evaluated high-resolution $(1.25-\mathrm{km}$ grid spacing) simulations of the Regional four cycles averaged over the S1 period of July 1, 2009 through April 22,2010

Atmospheric Modeling System (RAMS) over east-central Florida during the 1999 and 2000 summer months. They showed that the temperature and wind-speed RMSE for a 24-h forecast corresponding to the 12 UTC cycle had very similar temporal structure to the current results. Their peak temperature (wind speed) RMSE reached $3.75 \mathrm{~K}$ $\left(2.5 \mathrm{~m} \mathrm{~s}^{-1}\right)$ at the end of the $9-\mathrm{h}(7-\mathrm{h})$ forecast. In comparison, the NCAR-AirDat system has a peak temperature (wind speed) RMSE of $2.5 \mathrm{~K}\left(1.9 \mathrm{~m} \mathrm{~s}^{-1}\right)$ at the end of 6-h (12-h) forecast for the 12 UTC cycle (see Figs. 3, 4).

Jones et al. (2007) examined the RMSE of the 48-h MM5 ensemble forecasts over the northeast US at $12-\mathrm{km}$ horizontal resolution. They showed that the temperature RMSE approached $2.8 \mathrm{~K}$ and increased with the forecast length, which is similar to the current results. Their windspeed RMSE exhibited strong diurnal cycles with errors in the range of 2-2.8 $\mathrm{m} \mathrm{s}^{-1}$, while the current results show relatively smaller errors in the range of $1.5-2.1 \mathrm{~m} \mathrm{~s}^{-1}$. Jones et al. (2007) also showed that the wind-direction RMSE in their simulations had similar time tendencies to Case et al. (2002), i.e., increasing from $40^{\circ}$ to $55^{\circ}$ at the end of the 48-h forecasts in warm season (May-September), and from $30^{\circ}$ to $45^{\circ}$ in cool season (October-March). The WRF-RTFDDA wind-direction RMSE in the current study consistently exhibits the same time tendency for both 
RMSE averaged between 20100522-20100909
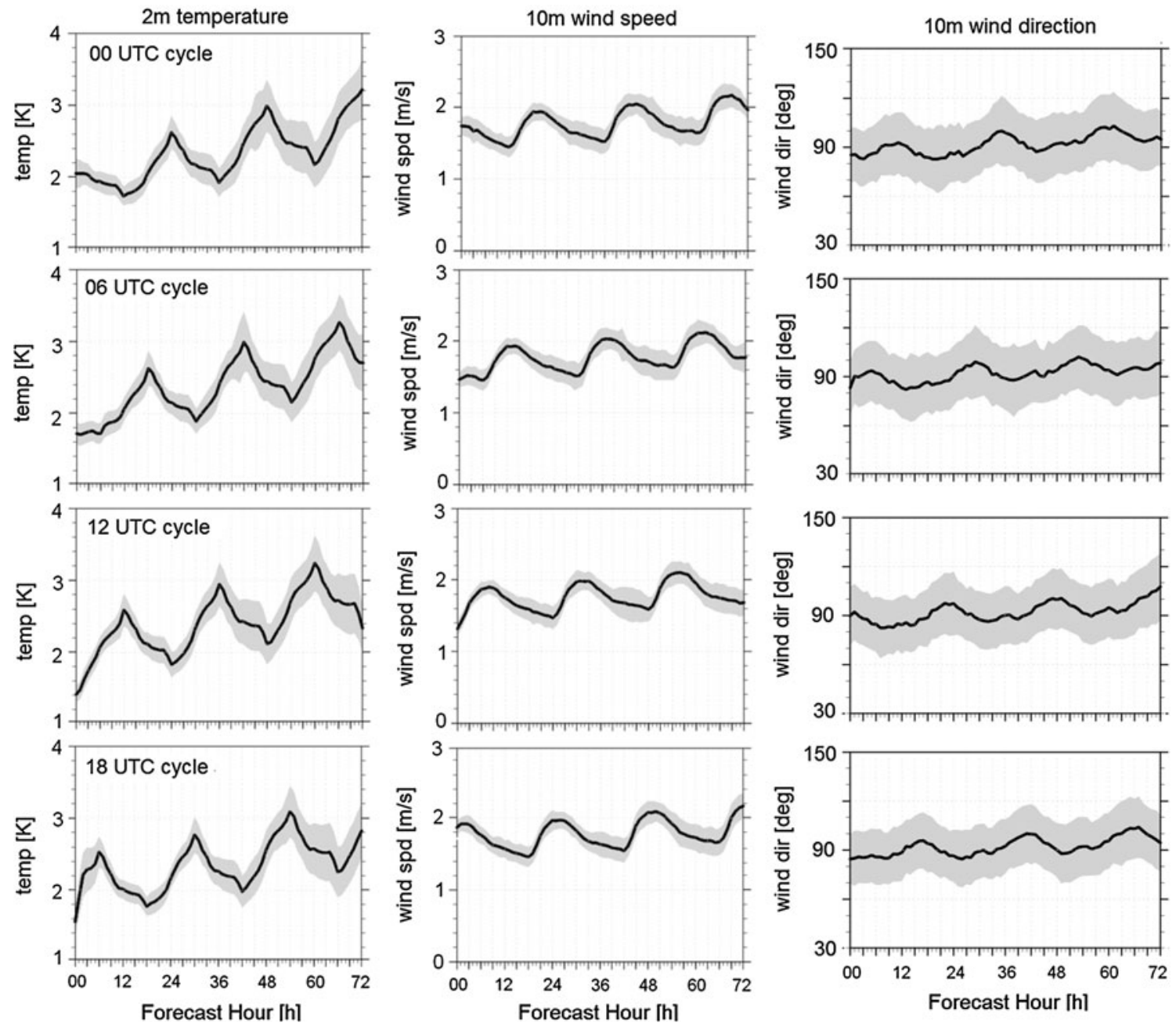

Fig. 4 Same as Fig. 3 except for the 0- to 72-h forecast lead time averaged over the S2 period of 22 May 2010 through 9 September 2010

cool and warm seasons, with higher RMSE in the range of $90^{\circ}-95^{\circ}$ within the 72 -h forecasts and a daily fluctuation of $\pm 5^{\circ}$. The higher mean RMSE in our WRF-RTFDDA simulations is likely related to large wind-direction errors over the Rocky Mountain areas where the model tends to have a difficulty in resolving the wind direction realistically due to the complex terrain.

The biases of temperature and wind speed as a function of forecast lead time averaged over the $\mathrm{S} 1$ and $\mathrm{S} 2$ periods for the 12 UTC cycles are presented in Fig. 5. The growth of temperature and wind-speed RMSE during the first few hours of the forecasts seen in Fig. 3 appears to be related to the increasing negative biases of the respective variables during the same time period (Fig. 5). The averaged maximum biases reach $-1 \mathrm{~K}$ for temperature and $-0.5 \mathrm{~m} \mathrm{~s}^{-1}$ for wind speed during the S1 period. At the end of the 24-h forecasts the average temperature biases decreased to zero while the total variances (represented by the yellow shadings) increased to $\pm 2 \mathrm{~K}$. The averaged wind-speed biases stay approximately constant in the second half of the 24-h forecasts with positive values not exceeding $0.3 \mathrm{~m} \mathrm{~s}^{-1}$ and total variances in the range of $\pm 1.3 \mathrm{~m} \mathrm{~s}^{-1}$. Both the temperature and wind-speed biases during the $\mathrm{S} 2$ period show strong diurnal variations (Fig. 5). The gradual increases of the averaged negative temperature biases as well as the total variance correlate well with the gradual increase of temperature RMSE in Fig. 4. For wind speed, biases stay nearly unchanged during the 72-h forecasts; however, the total variances increase slowly and reach $\pm 1.6 \mathrm{~m} \mathrm{~s}^{-1}$ at the end of the 72-h forecasts, which also corresponds well to the gradual increase of wind-speed RMSE seen in Fig. 4.

Figure 6 shows the correlation of temperature and wind speed between the model forecasts and the observations as a function of forecast lead time for the 12 UTC cycle. Apparently, the correlation is much higher for temperature than wind speed for both S1 and S2 periods. Gradual decreases in the correlation with the forecast lead time are noticed for both temperature and wind speed; however, the 
Fig. 5 Bias of temperature (left panels) and wind speed (right panels) as a function of forecast lead time for the 12 UTC cycle averaged over the $\mathrm{S} 1$ period (upper panels) and S2 period (lower panels). The raw biases are averaged over all stations and all available cycles, and are represented by the continuous black lines. The yellow shadings represent total variance, while the gray shadings represent the variance between different 12 UTC cycles bias averaged between 20090701-20100422
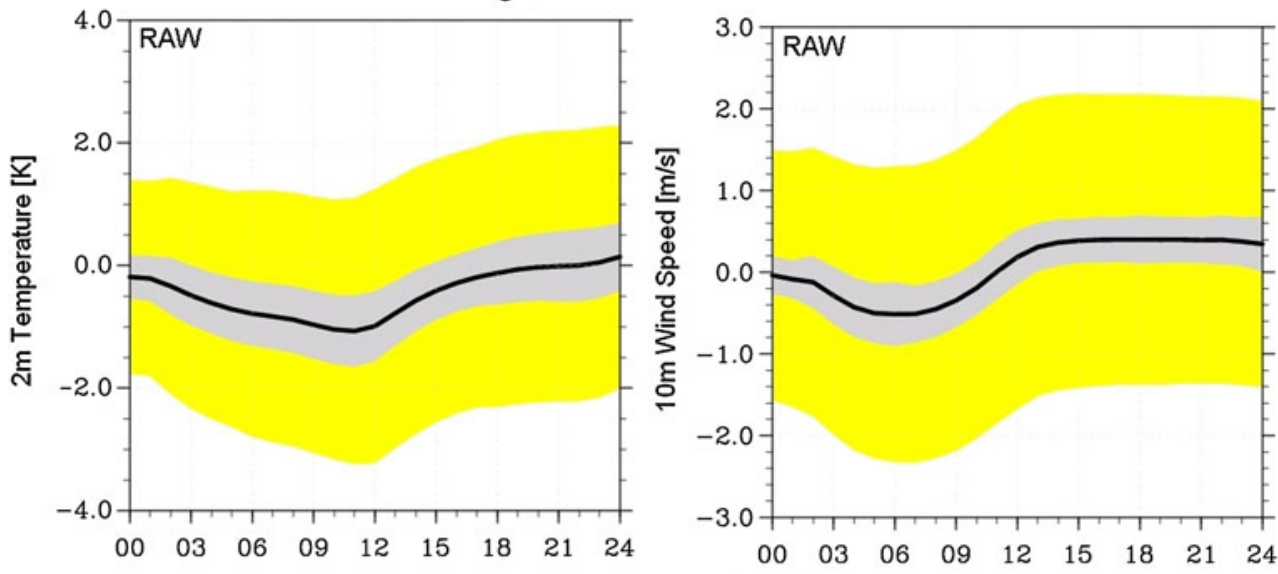

bias averaged between 20100522 - 20100909

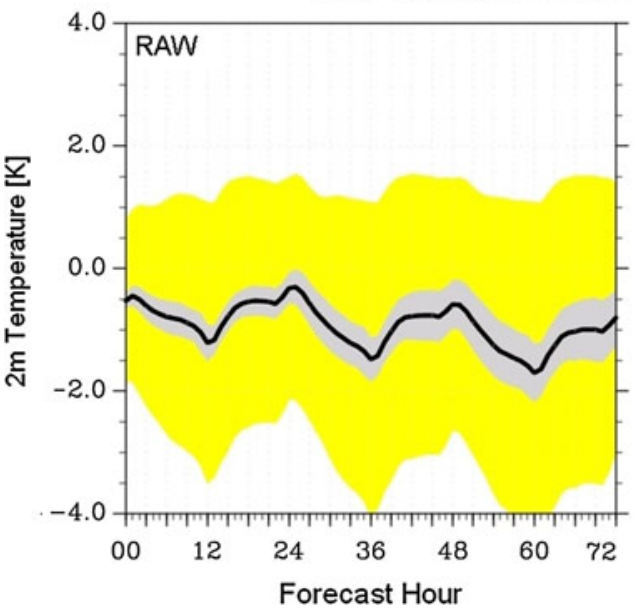

variances do not show a clear trend. Temperature (wind speed) shows well-defined (less well defined) diurnal variations in correlation during the 72 -h forecasts.

\subsection{Seasonal variation of the forecast errors}

Figures 7 and 8 show the seasonal variability of temperature biases and wind-speed biases, respectively, as a function of the forecast hours during the S1 period. For 2-m temperature (Fig. 7), the model shows positive biases up to $1.5 \mathrm{~K}$ in nighttime and cold biases with peak values reaching $-1.5 \mathrm{~K}$ in daytime during the fall, winter, and spring. The cold biases have two peaks: one in November, and another higher peak between February and April. Biases are lower in summer, with generally weak positive biases $(<0.5 \mathrm{~K})$ in the morning and early afternoon. During the summer, cold biases occur during the late afternoon and early evening hours. Overall, the model system underpredicts the amplitude of the diurnal evolution of 2-m temperature as reflected by warm biases at night and cold biases in the afternoon, which suggests a systematic deficiency in the WRF physical parameterization schemes especially the radiation scheme and the treatment of advection (e.g., Rostkier-Edelstein and Hacker 2010). Insufficient vertical levels within the boundary layer might also contribute to the model biases as the current system only has 13 vertical levels between the surface and the 1.5$\mathrm{km}$ height. The model biases could be effectively mitigated through the assimilation of surface observations as noted by Rostkier-Edelstein and Hacker $(2010,2013)$ in their single-column model-ensemble filter experiments.

Surface wind speed is strongly positively biased (Fig. 8) at night during the entire study period, with the averaged biases ranging between 0.5 and $1.0 \mathrm{~m} \mathrm{~s}^{-1}$, and peaks up to $2 \mathrm{~m} \mathrm{~s}^{-1}$ at times. During the late spring and summer, there are strong negative biases in the afternoon with a peak of $-1.5 \mathrm{~m} \mathrm{~s}^{-1}$. The negative biases in the afternoon may be related to the limited ability of the $4-\mathrm{km}$ grid model to represent the afternoon convection, while the positive nighttime biases might be related to the known deficiencies of WRF boundary-layer parameterizations under stable conditions. The nighttime positive wind speed biases are also closely correlated to the nighttime warm temperature bias, likely pointing to possible excessive mixing of the surface layer in 
Fig. 6 Correlation coefficients of the observed and simulated temperature (left panels) and wind speed (right panels) as a function of forecast lead time for the 12 UTC cycle during the $\mathrm{S} 1$ period (upper panels) and S2 period (lower panels). The mean and variance are represented by thick black lines and gray shadings, respectively
Fig. 7 Temporal variations of the domain-averaged daily temperature biases as a function of forecast lead time for each of the four cycles during the period of July 1, 2009 through April 22, 2010 (the S1 period; the forecast date is written in the format month/day along the $y$ axis) corelation averaged between 20090701-20100422
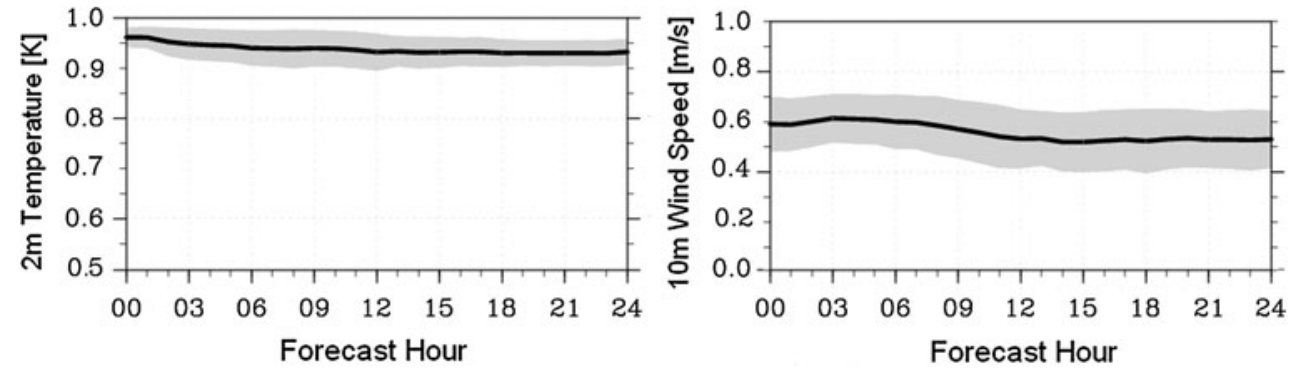

corelation averaged between 20100522 - 20100909
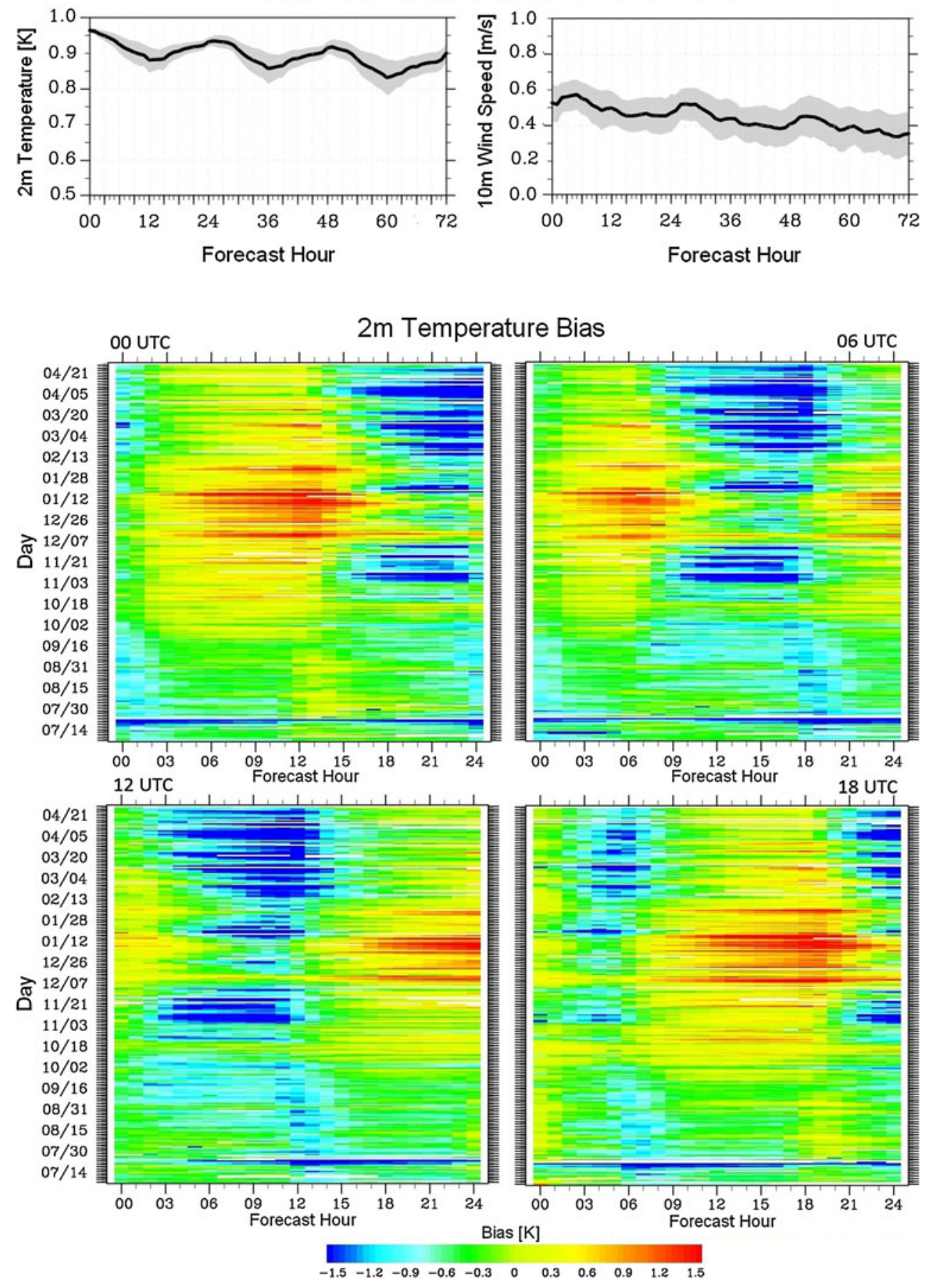
Fig. 8 Same as Fig. 7 except for the domain-averaged daily wind-speed biases

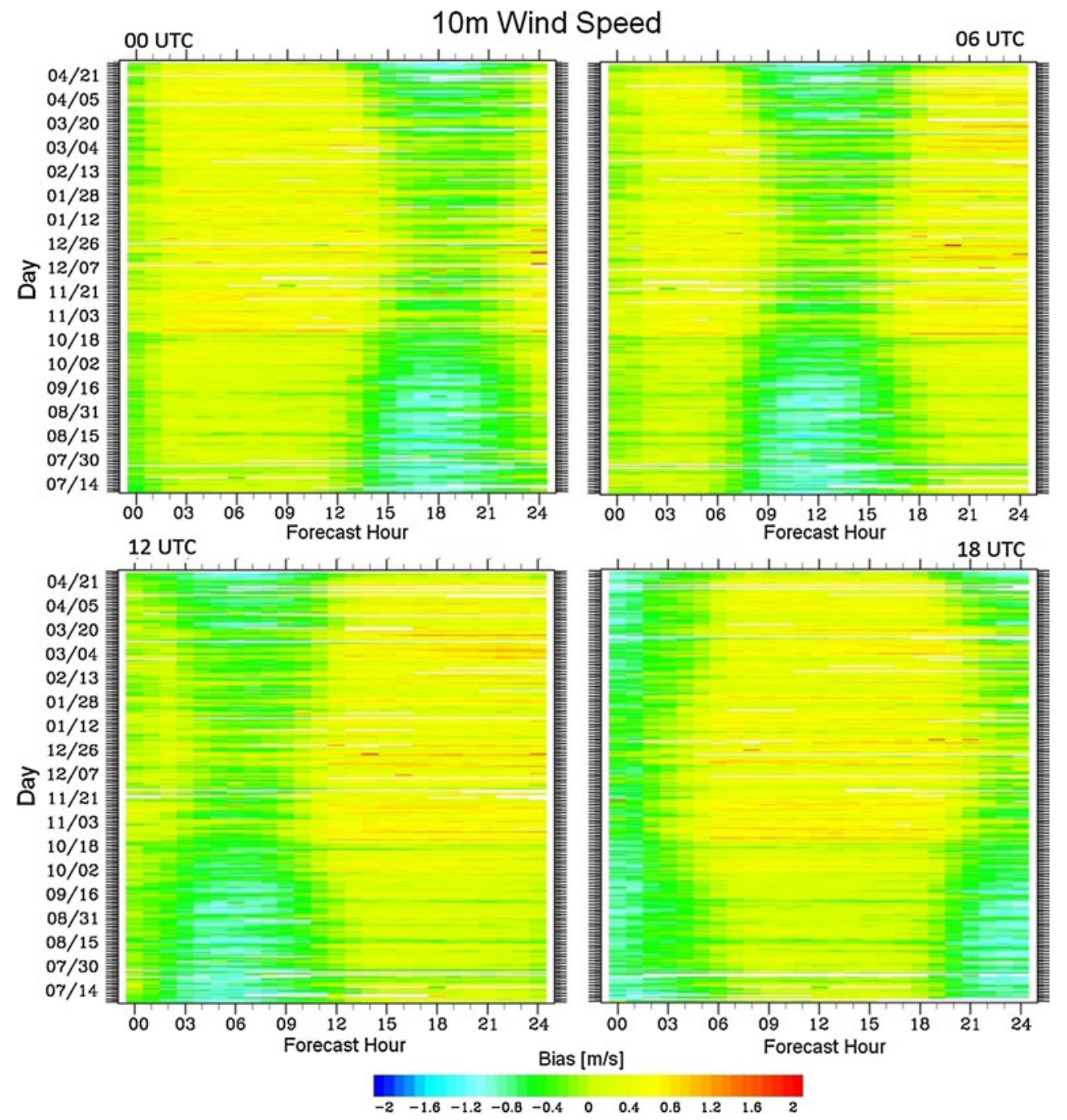

the model, which may be in turn due to small-scale terrain drag that is unresolved by the current weather models (Steeneveld et al. 2008). Steeneveld et al. (2009) showed that gravity wave drag due to small obstacles, mountains and hills could reach the equivalent magnitude as the turbulent drag and could modify the wind speed sufficiently.

The temperature and wind-speed biases as a function of forecast lead time for the 00 UTC (late afternoon over CONUS) cycle and 12 UTC (early morning over CONUS) cycle during the S2 period are shown in Fig. 9. As in the case for the S1 period, warm (positive) biases in the nighttime and cold (negative) biases in the afternoon are evident for temperature (wind speed) during the $\mathrm{S} 2$ period. The daytime cold bias reaches $-1.5 \mathrm{~K}$ during the late afternoon hours, while the nighttime warm bias is generally less than $0.3 \mathrm{~K}$. The wind speed tends to be under-predicted by $-1.5 \mathrm{~m} \mathrm{~s}^{-1}$ in the afternoon. Between the late afternoon (i.e., 00 UTC) cycle and the early morning (i.e., 12 UTC) cycle, relatively small differences are noticed for wind speed during the entire S2 period; however, the temperature biases exhibit significant differences especially during June, July, and August (Fig. 9). The temperature biases from May to early June and from late August to September are greater than those in the other months for both cycles. Spring weather over CONUS is characterized by substantial increases in temperature and wind speed with a gradual decrease in precipitation, while in the autumn and winter, the weather conditions are nearly the opposite. In the summer, unstable conditions with convective activities dominate the weather over CONUS. Thus, it appears that the seasonal changes in the forecast biases more or less reflect the model's varying skills under different weather regimes, for example, treatment of shallow cumulus convection (e.g., Angevine 2005; Angevine et al. 2010).

The mean RMSE of the S1 and S2 periods seen in Figs. 3 and 4 contains both systematic (i.e., bias) and random-error components. The variance, also known as the 
Fig. 9 Temporal variations of the domain-averaged daily temperature biases (upper panels) and wind-speed biases (lower panels) as a function of forecast lead time for the 00 UTC cycle (late afternoon, left panels) and 12 UTC cycle (early morning, right panels) during the period of May 22, 2010 through September 9, 2010 (the S2 period)
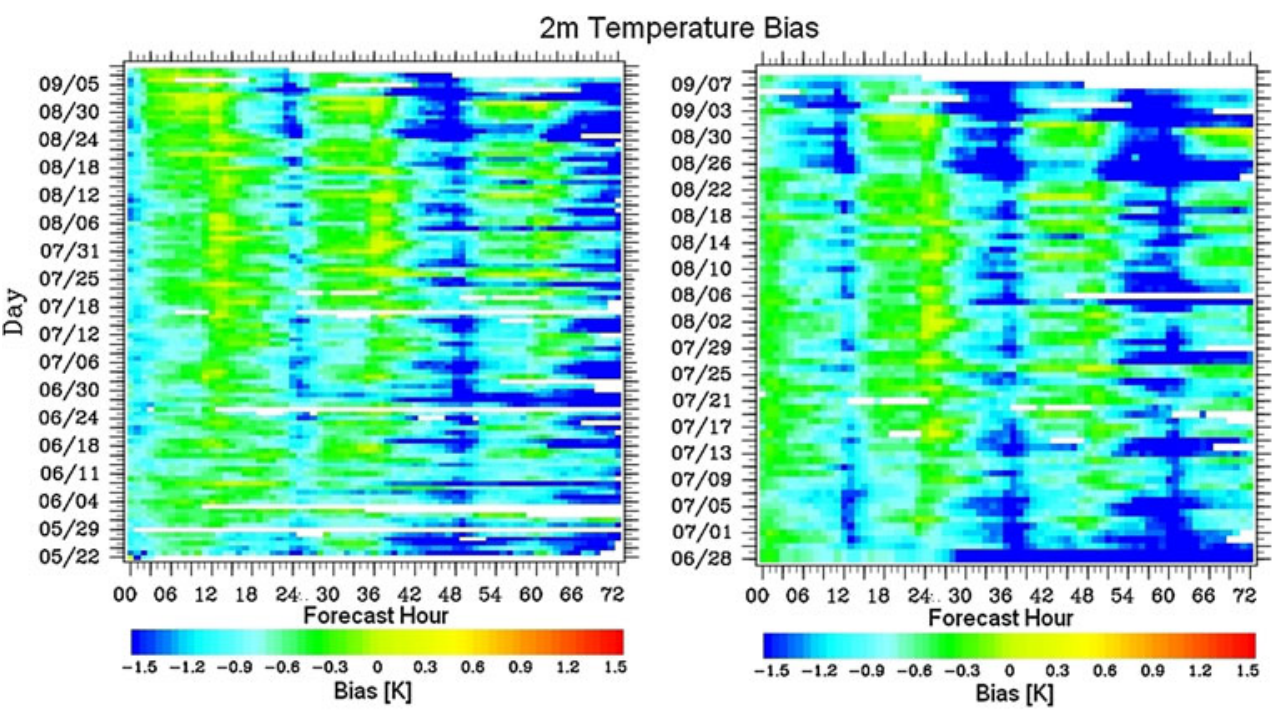

10m Wind Speed Bias
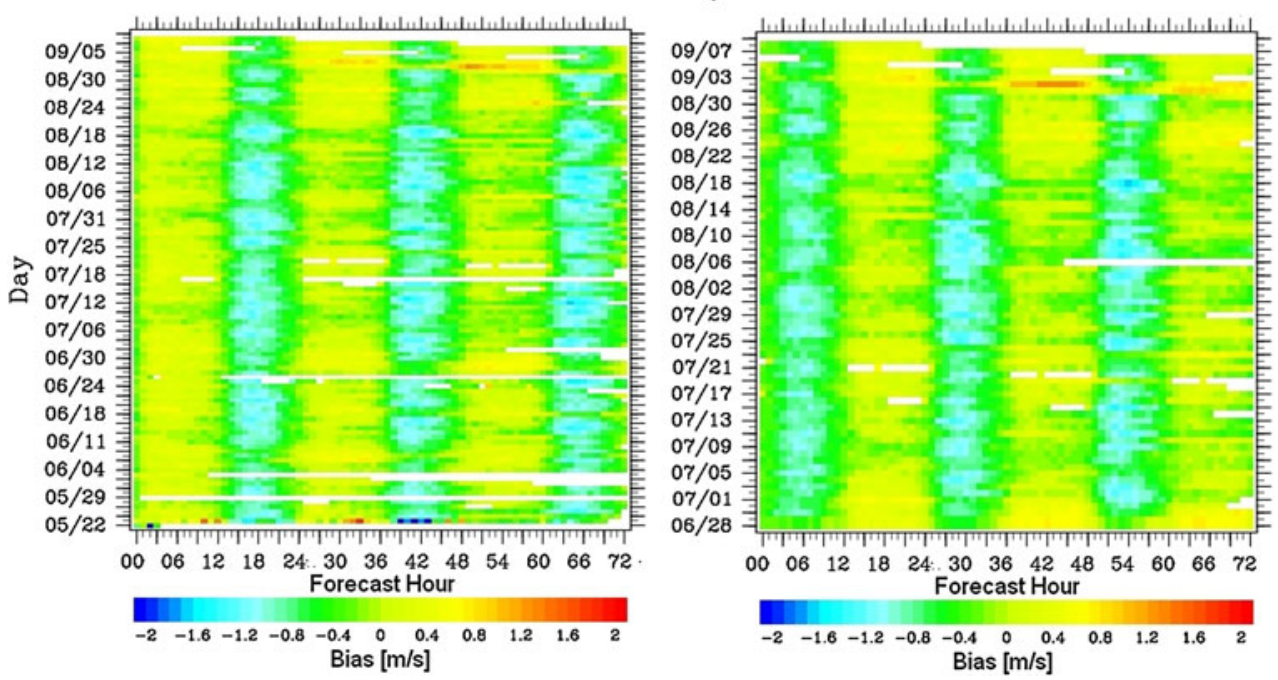

centered root-mean square error $\left(\mathrm{CRMSE}^{2}\right)$, is the random component defined as follows,

$$
\begin{aligned}
\mathrm{CRMSE}^{2} & =1 / N \sum_{i=1}^{N}\left[\left(C_{\mathrm{f}}(i)-\bar{C}_{\mathrm{f}}\right)-\left(C_{\mathrm{O}}(i)-\bar{C}_{\mathrm{O}}\right)\right]^{2} \\
& =\mathrm{RMSE}^{2}-\mathrm{BIAS}^{2}
\end{aligned}
$$

and is partly caused by the under-resolved small-scale or high-frequency phenomena such as convective cells by the 4-km grid model. The mean RMSE in the S2 period (Fig. 4) shows a much stronger diurnal signature than that in the S1 period (Fig. 3) and the most likely reason is that the mean RMSE in the S1 period is obtained by averaging across multiple seasons with differing diurnal bias distributions.

\subsection{Error geographical distributions}

Figure 10 displays the geographical distributions of the mean bias of 10-m wind speed, 10-m wind direction and 2-m temperature for the 00 UTC (late afternoon) and 12 UTC (early morning) cycles. The biases are computed for the 24-h forecasts, and the averaging is done for all forecast cycles of the $\mathrm{S} 1$ period. The wind-speed forecasts for the stations in the western portion of the domain, mostly along the slopes of the Rocky Mountains and in the Central Valley of California, have large negative biases at 00 UTC, some as low as $-3 \mathrm{~m} \mathrm{~s}^{-1}$. The wind-speed biases are smaller at most coastal mountainous locations at 12 UTC. In contrast, positive wind-speed biases of up to $2 \mathrm{~m} \mathrm{~s}^{-1}$ can be seen in the eastern coastal areas, as well as the northwestern coastal areas, including northern California, Oregon, and Washington for both cycles. Stations in the Midwest including the Great Plains exhibit relatively smaller wind-speed biases for both cycles.

The wind-direction biases show irregular distributions in the eastern areas with large variations among stations. The biases, however, are strongly negative (counterclockwise) over the Rocky Mountains with values reaching $-25^{\circ}$, and 


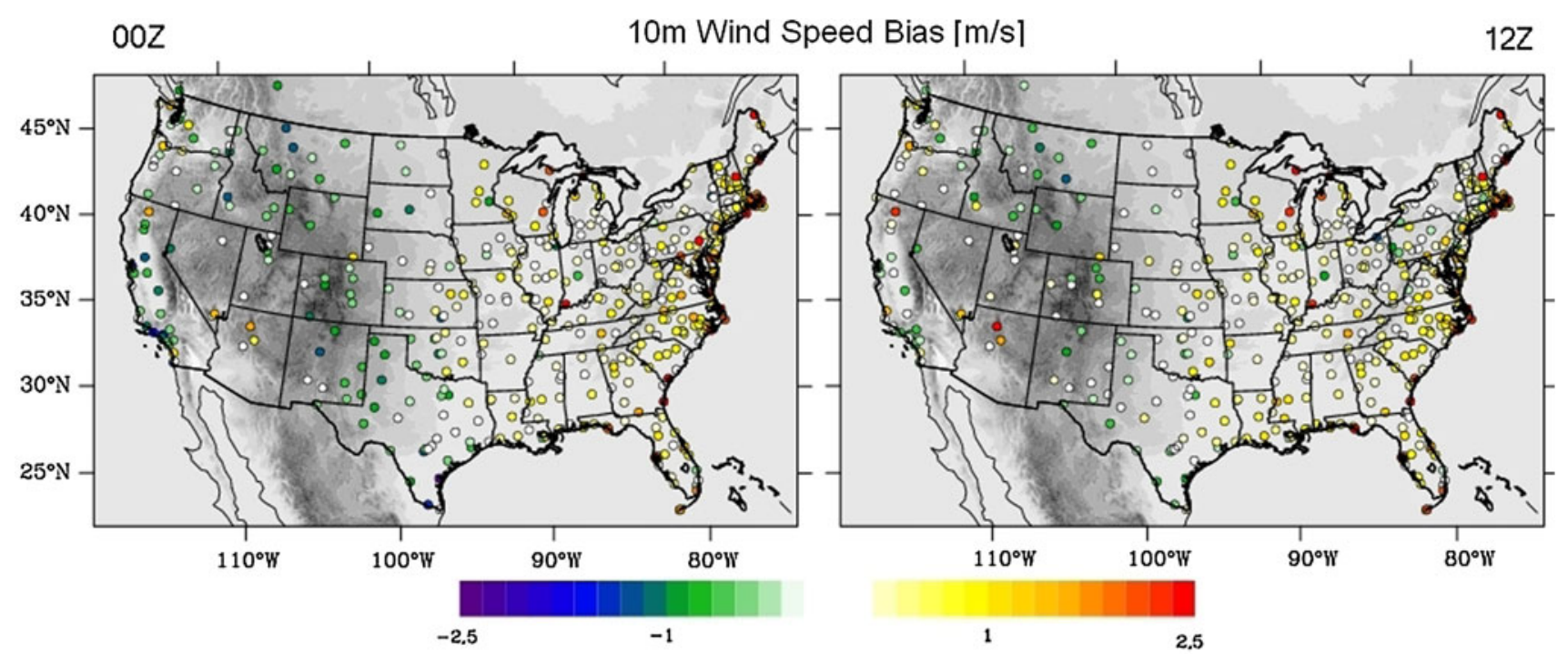

$00 Z$

10m Wind Direction Bias [deg]
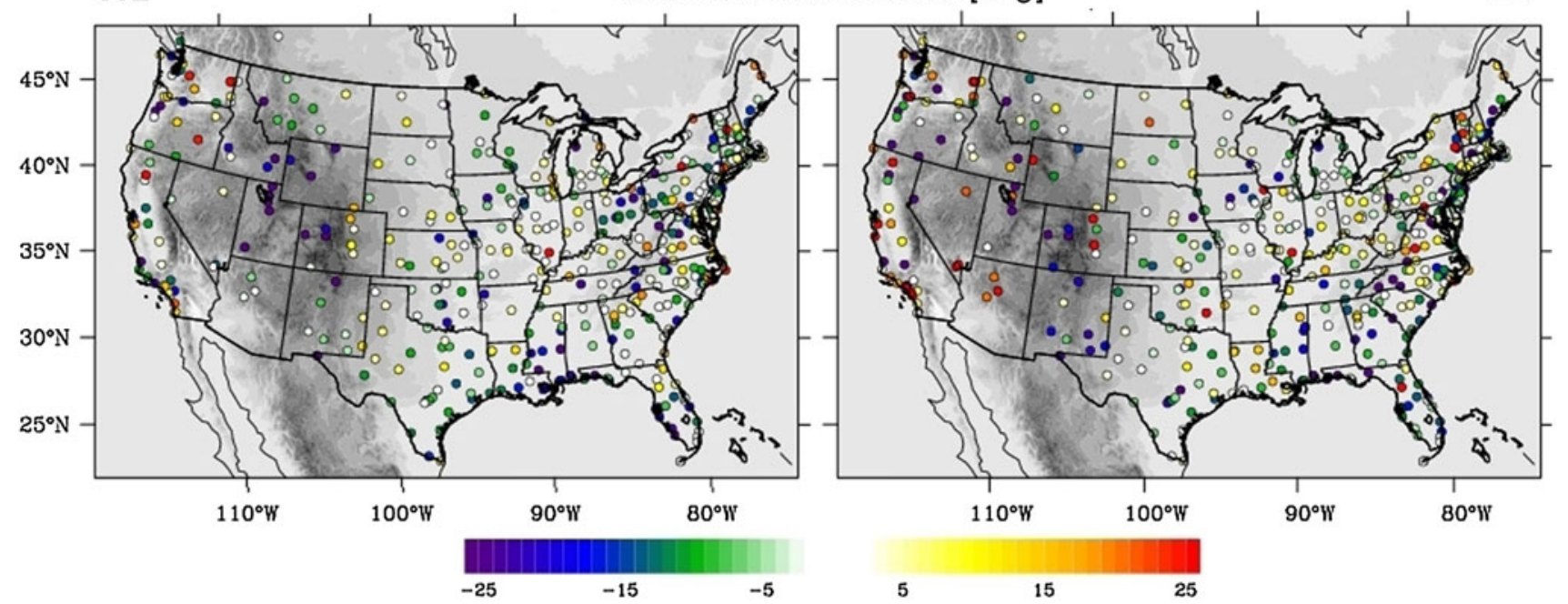

$00 Z$

2m Temperature Bias [K]

122

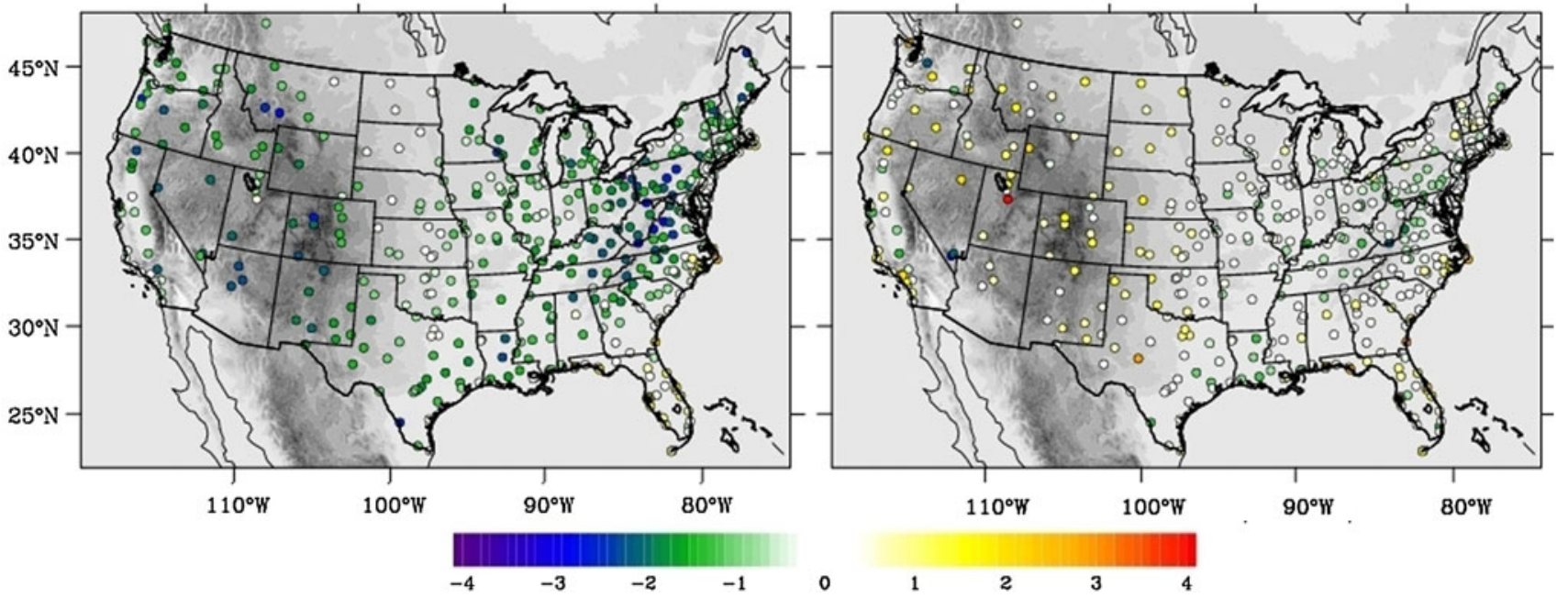

Fig. 10 Geographical distribution of biases for the S1 period: 00 UTC (left panels) and 12 UTC (right panels). The biases of the 24-h forecasts are averaged over all valid cycles within S1 
positive biases of up to $20^{\circ}$ are observed along the western Rocky Mountain slopes for the 00 UTC cycle. Furthermore, the wind-direction biases on the slopes are about $5^{\circ}$ greater for the 12 UTC cycle when compared to the 00 UTC cycle. The wind-direction biases in the mountainous regions may indicate some deficiencies in the model's representation of the topographic forcing, which likely causes systematic flow shifts. In WRF simulations over the Pacific Northwest at the 12-km grid spacing, Mass and Ovens (2011) also noted over-prediction of the near-surface wind speed and wind-direction errors at low levels in areas of complex terrain in which the flow tends to be too geostrophic. They attributed the causes of the model errors to the lack of sub-grid terrain friction in WRF and subsequently introduced an algorithm to mitigate the errors in wind speed and direction.

The temperature biases also exhibit notable spatial variations between the east states and the west states (Fig. 10). Some large cold biases up to $-4.0 \mathrm{~K}$ occur over the Appalachian Mountains, the valleys of California and Washington, and over the Rocky Mountains for the 00 UTC cycle. The Northern and Southern Plains show negligible biases for the 00 UTC cycle, but warm biases up to $1.5 \mathrm{~K}$ for the $12 \mathrm{UTC}$ cycle. Compared to the $00 \mathrm{UTC}$ cycle, the 12 UTC cycle shows mainly positive biases over CONUS, except for a region along the Appalachian range where negative biases in the range of $-1.5 \mathrm{~K}$ are found.

The larger daytime cold biases associated with the high mountains for the 00 UTC cycle constitute a complicated modeling challenge. The causes of the larger biases may be related to (a) imperfect atmospheric radiation transfer over the high terrain; (b) inaccurate representation of the landuse properties; (c) truncated valleys/peaks of mountain ranges due to limited model grid resolution; (d) inaccurate mountainous cloud simulation; and (or) (e) uncertainty in the model surface-snow process parameterization within the land-surface model (LSM) (e.g., Barlage et al. 2010; Mass and Owens 2013). An increasing trend in removing these error sources from the NWP systems are currently observed in the modeling community.

Barlage et al. (2010) introduced a time-varying albedo formulation that increases the fresh snow albedo in the WRF-Noah LSM and improves the magnitude and timing of seasonal maximum snow-water equivalent (SWE) in the Colorado Rocky Mountains. Minor improvements in the averaged SWE were also obtained by introducing adjustments to surface exchange coefficients in the stable boundary layer, as well as the surface roughness length over snow. The same authors also found that introduction of terrain orientation and slope dependence did not affect the simulated SWE seasonal maximum; however, the diurnal distributions of incoming solar radiation between the east- and west-facing slopes were changed. These changes between the slopes might affect the convective precipitation, accumulation and ablation of snow, and hence, directly change the distributions and amplitude of the temperature biases along the mountain ranges.

Biases in coastal areas are affected by the different diurnal land-water heating, and are subjected to the imperfect simulations of the magnitude and phases of sea and land breezes. Notice that in the current study, the nighttime warm biases in the coastal areas nearly disappear during the daytime. Croke et al. (2010) suggested that the diurnal signal in the temperature biases is linked to the nocturnal damping of the sea breezes by the warm coastal waters in the fall. Case et al. (2008) investigated improvements in the land-surface initialization of the WRF model using NASA Land Information System (LIS) conditions. The drier initial soil states in their simulations improved the simulation of the timing and evolution of a sea breeze over northwestern Florida, which resulted in a reduction in both the nocturnal warm bias, as well as the daytime cold bias.

\section{Correlation of forecast biases terrain heights}

Complex terrain significantly impacts weather systems that pass by and greatly modulates the local and regional weather processes as reported by Roux et al. (2009) and Mass and Ovens (2011) in the recent versions of WRF over the Northwest Pacific area. More recently, Jiménez and Dudhia (2012) showed positive bias $\left(\sim 1 \mathrm{~ms}^{-1}\right)$ over the valleys and plains and large negative bias $\left(-3 \mathrm{~m} \mathrm{~s}^{-1}\right)$ at the hills and mountains. On average, both biases are compensated although the uneven sampling of the wind by the larger number of stations located in plains and valleys comparing to number of mountain stations results in an overall positive bias. Jiménez and Dudhia (2013) also found large magnitude of biases of the wind direction (RMSE of $80^{\circ}$ ) over the areas of complex terrain and these errors were dependent inversely on the surface wind speed. In this section, we present detailed analyses of the model biases in the context of terrain including their seasonal variability and the terrain dependency.

\subsection{Seasonal bias variability for the lower and the higher elevation stations}

Figure 11 shows the distributions of the mean temperature bias for all 12 UTC forecast cycles in the S1 period averaged both over all stations and over stations with terrain heights either above or below $600 \mathrm{~m}$ above seal level (ASL). The 600-m threshold was chosen arbitrarily with the purpose of distinguishing the low-altitude coastal areas from the high plains and mountains. The results indicate that the high-elevation stations have much larger warm biases during the nighttime with maxima exceeding $1.5 \mathrm{~K}$, 

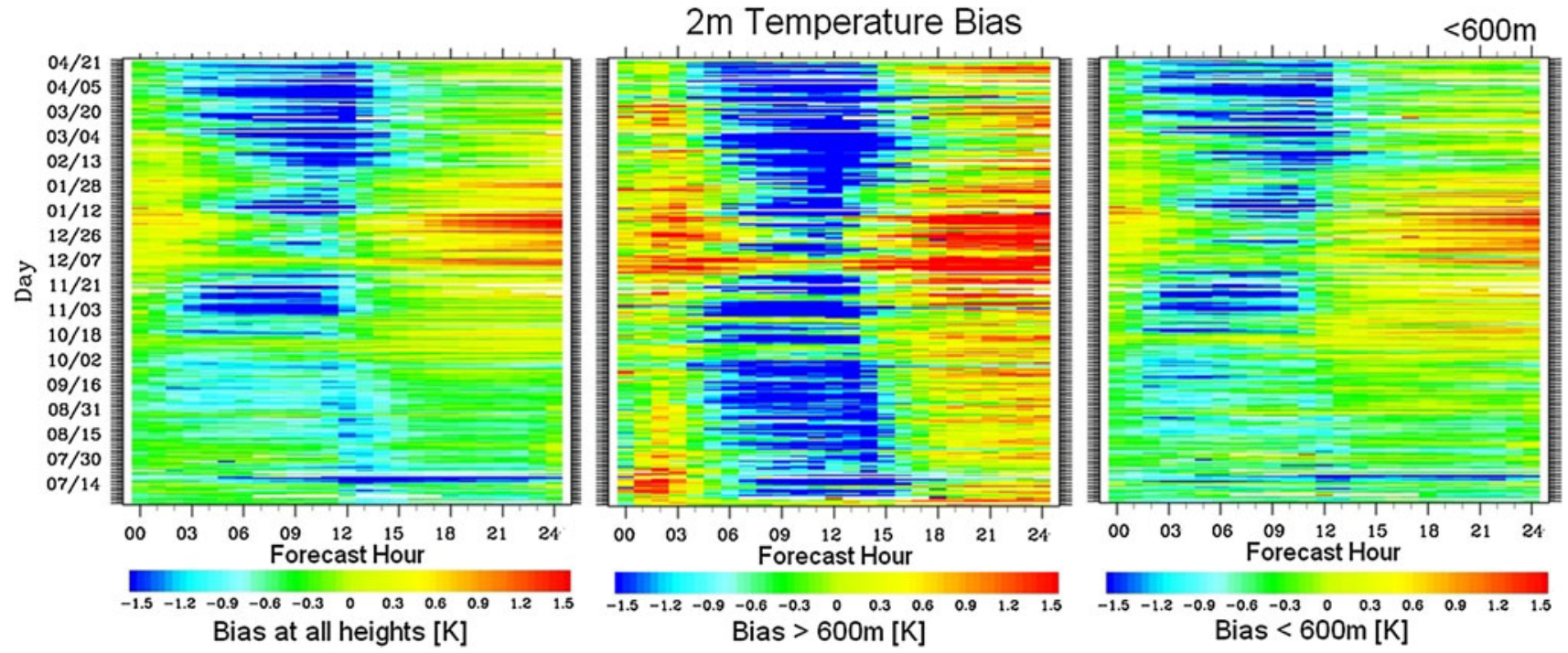

Fig. 11 Mean temperature biases in the S1 period as a function of forecast lead time averaged over all stations (left panel), over stations with terrain height above $600 \mathrm{~m}$ (center panel) and over stations with terrain height below $600 \mathrm{~m}$ (right panel) for the 12 UTC cycles

and cold biases during the daytime $(>-1.5 \mathrm{~K})$. The nighttime warm biases are much greater in the winter than the other seasons during the $\mathrm{S} 1$ period. During the summer, convection that frequently occurs in the afternoon may lead to a decrease of the nighttime warm biases. This appears to be the case especially for the low-elevation stations (Fig. 11). As a matter of fact, even the western stations exhibit small cold biases at night (not shown).

The low-elevation stations tend to show cold biases for both the daytime and nighttime for the reasons discussed above; however, the amplitude of the cold biases exhibits strong seasonal dependence. For example, in the summer, the daytime negative biases are normally greater than $-0.8 \mathrm{~K}$; but in the spring, the cold biases in the daytime could reach as high as $-1.4 \mathrm{~K}$. At the nighttime, slightly negative biases in the range of $-0.3 \mathrm{~K}$ exist during the spring and summer, with peak values around $-1.0 \mathrm{~K}$ during the middle of June. During December and January, the negative biases are replaced by positive biases and the maximum values could reach $1.2 \mathrm{~K}$. The negative biases, seen in Fig. 10, for the eastern stations are then consistent with the domain-averaged biases for the stations below $600 \mathrm{~m}$, which are around $-0.2 \mathrm{~K}$. The small magnitude of this domain-averaged negative bias is due to the dominance of the coastal stations located in Florida and North Carolina for which small positive biases are found.

\subsection{Dependence of biases with terrain height for different forecast cycles}

To further analyze the dependence of biases on the terrain height, we divided the surface stations into 11 groups based on the stations' elevations: 15-46, 47-99, 100-167,
168-233, 234-287, 288-396, 397-579, 580-1,004, 1,005-1,481, 1,482-2,117, 2,118 $\mathrm{m}$ and higher. Coincidently, each group contains approximately the same number of stations.

Figure 12 shows the 2-m temperature biases as a function of the terrain elevation averaged over the S1 period. The low-elevation stations always show weak cold biases, regardless of the cycles, with smaller biases at nighttime (i.e., roughly $-0.2 \mathrm{~K}$ for the $12 \mathrm{UTC}$ cycle). All stations exhibit cold biases for the 00 UTC and 18 UTC cycles while the stations above $400 \mathrm{~m}$ for the 12 UTC cycle and above $600 \mathrm{~m}$ for the 06 UTC cycle show warm biases. Thus, at the higher elevations $(>600 \mathrm{~m})$, the temperature biases display well-defined diurnal variability, with strongly negative bias (up to $-2.0 \mathrm{~K}$ ) in the daytime (18 and 00 UTC cycles) but moderately positive (up to $1.0 \mathrm{~K}$ ) at night. The largest temperature biases are found for the highest elevations, which is also consistent with the findings in other mesoscale model experiments. For example, $\mathrm{Xu}$ et al. (2009) examined the WRF-ARW model biases in the complex terrain of Southwest Asia from 1 to 31 May 2006. The 2-m temperature errors in their simulations were closely related to the heterogeneity in terrain structure, with larger forecast errors located in the higher elevation terrain.

The bias distributions presented in Fig. 12 are also consistent with the individual cycle-averaged results shown in Fig. 10, showing that the strongest cold biases exist over the Appalachian Mountains in the eastern part of the model domain where the average elevation is roughly $900 \mathrm{~m}$ with peaks around $2,100 \mathrm{~m}$. In this elevation range, the largest cold biases come from the 00 UTC cycle and range from -1.5 to $-4.0 \mathrm{~K}$. Above $2,100 \mathrm{~m}$ (the Rocky Mountain 
Fig. 12 Temperature biases as a function of the terrain elevation averaged over the S1 period. The dashed-dot lines are the averaged biases for all stations higher than the elevation threshold. The continuous horizontal lines are the average over all station elevations

\section{D2 20090701-20100422}
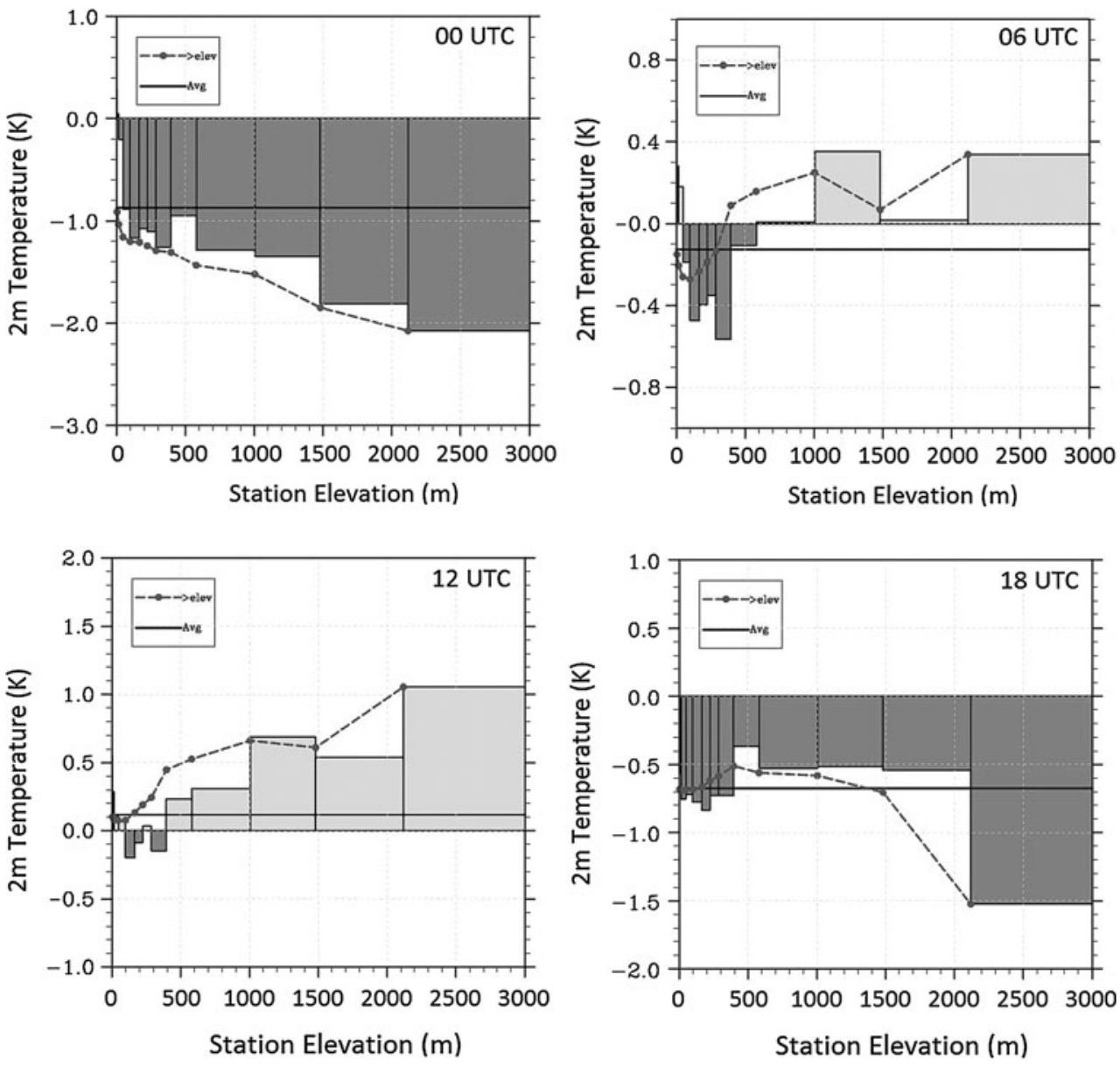

stations), the average cold biases are the biggest during the daytime but shift to weak warm biases during the night; however, large spatial variations of biases are also evident within this elevation range. During the daytime, the stations with small cold biases are located mostly in the central part of the Rocky Mountains, and larger cold biases are present in the eastern and western parts of the Rockies, as well as near coasts in northern California, Oregon, and the Cascade Mountains of Washington. The latter may be related to the amount of moisture carried from the Pacific Ocean deep into the continental areas, as well as the imperfect representation of the convective cloud processes along the slopes of this complex topography. The localized over-prediction of precipitation on the windward slopes and over the broader leeward regions along the Oregon Cascades was observed with MM5 (Garvert et al. 2005a, b) and the Canadian Global Environmental Multiscale (GEM) model (Milbrandt et al. 2008) model. Lin and Colle (2009) reported over-prediction of snow by the WRF model along the Cascades' windward slopes due to the over-predicted maximum snow depositional growth, which resulted in rapid and excessive graupel (rimed snow) fallout.
The model wind directions (Fig. 13) exhibit negative biases of approximately $-9^{\circ}$ for the stations with elevations below $600 \mathrm{~m}$ ASL. The smallest wind-direction errors are seen for the stations with altitudes between 600 and $1,000 \mathrm{~m}$, while the highest errors are found at the highest stations with elevation in excess of $2,100 \mathrm{~m}$. The biases from forecast cycles 06 and 12 UTC, which represent the nocturnal and early morning conditions, show similar structure with a positive bias of $4^{\circ}$ for stations located between 600 and $1,000 \mathrm{~m}, 11^{\circ}$ for stations $1,500-2,100 \mathrm{~m}$, a negative bias of $-12^{\circ}$ for stations $1,000-1,500 \mathrm{~m}$, and the largest negative bias of $-20^{\circ}$ for the highest stations situated above $2,100 \mathrm{~m}$. The 00 UTC afternoon forecasts show strong negative biases for stations located above $1,000 \mathrm{~m}$, reaching $-20^{\circ}$ at the highest station locations. The mid-day forecast conditions from the 18 UTC cycles produce small biases for station elevations between 600 and $2,100 \mathrm{~m}$, and positive biases of up to $8^{\circ}$ for the highest station locations.

The 10-m wind-speed biases presented in Fig. 14 show an interesting difference between the mid-elevation stations with consistently negative biases, and the low- and 
Fig. 13 Same as Fig. 12 except for the wind-direction biases

\section{D2 20090701-20100422}
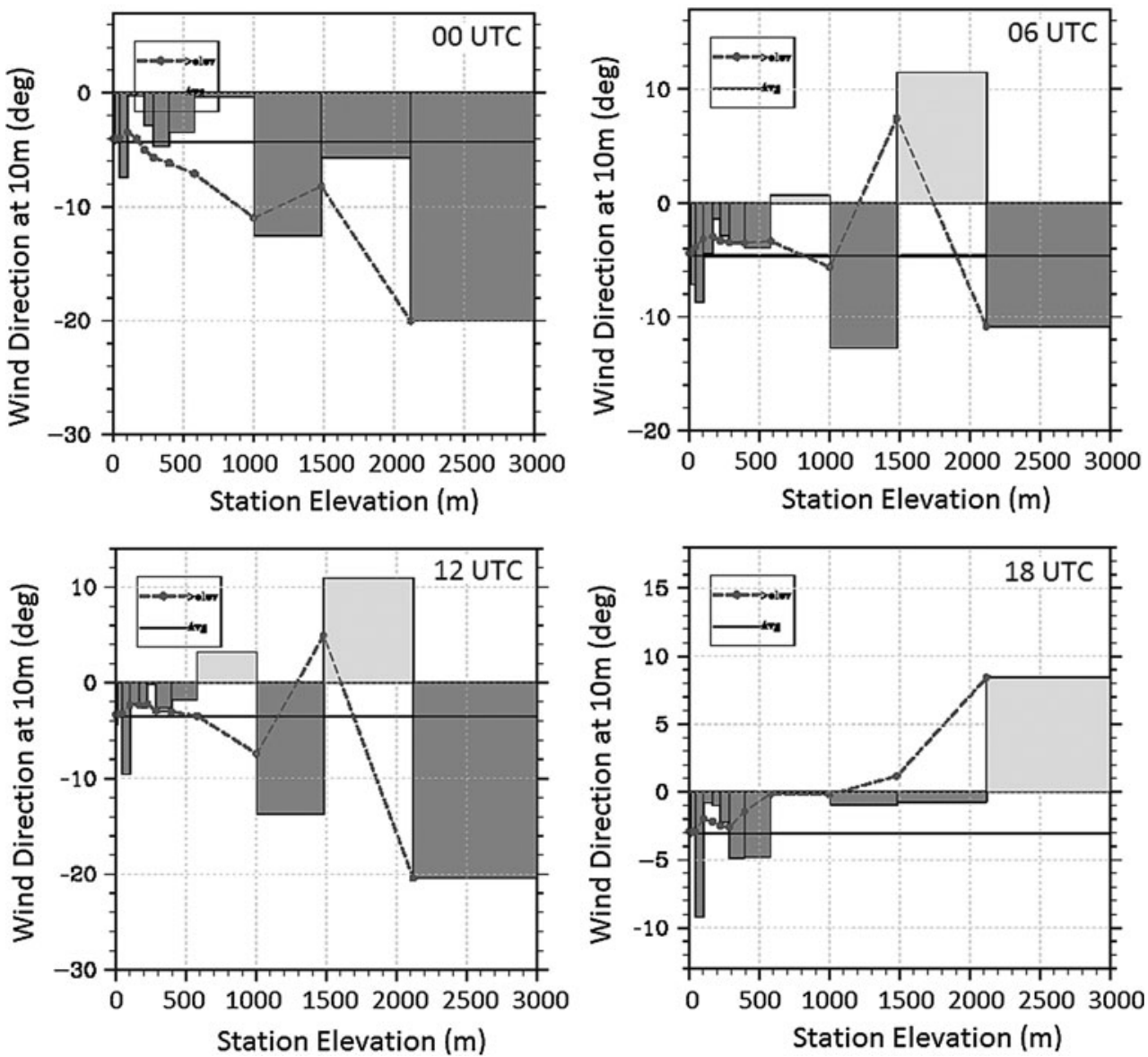

high-elevation stations where the bias sign changes between cycles. Strong diurnal variability is seen at the higher elevation stations located above 2,100 m, changing from a negative daytime bias of $-0.8 \mathrm{~m} \mathrm{~s}^{-1}$ to positive biases with a peak of $0.6 \mathrm{~m} \mathrm{~s}^{-1}$ during the early morning hours. The cycle-averaged biases in wind speed are small at many stations (see Fig. 10), and are most likely due to the cancellation of the positive and negative biases throughout the diurnal cycle. This is especially true for the majority of the Rocky Mountain stations. The biases at middle elevation stations between 1,000 and 2,100 m remain negative with a nocturnal minimum of $-0.3 \mathrm{~m} \mathrm{~s}^{-1}$ and mid-day negative peak of $-0.8 \mathrm{~m} \mathrm{~s}^{-1}$. The average negative wind-speed bias in Fig. 8 is the combined signature of the stations in the Great Plains, the California Coastal Range, and several stations with a weaker negative bias in the Rocky Mountains. At the low elevations, the biases are mostly positive with a maximum of $0.7 \mathrm{~m} \mathrm{~s}^{-1}$, except during the middle of the day when the biases become negative at each model elevation. When averaged across all cycles, the low-elevation stations indicate strong positive biases with the highest positive bias near the coastal locations, as well as stations around the Appalachian Mountains.
The nighttime wind-speed biases presented here are in agreement with the results provided by Roux et al. (2009) who also found that the wind-speed biases decreased from lower terrain to about $600 \mathrm{~m}$ ASL, and then increased with elevation toward the mountain peaks. The same authors noted that the lowest biases were seen at stations between 400 and 1,500 $\mathrm{m}$ ASL while the highest biases were identified at stations located near sea level and the higheraltitude mountains. This observation calls for future research on stable boundary-layer parameterizations over large mountain ranges.

\section{Summary}

Investigating the characteristics of model-forecast errors using various statistical and object-oriented methods is necessary for providing useful guidance to end-users and model developers as well. The NCAR-AirDat weather research and forecasting (WRF)-based real-time fourdimensional data assimilation (RTFDDA) and forecasting system, running operationally over a contiguous United States (CONUS) domain at a 4-km grid spacing with four forecast cycles daily from June 2009 to September 2010, 
Fig. 14 Same as Fig. 12 except for the wind-speed biases
D2 20090701-20100422
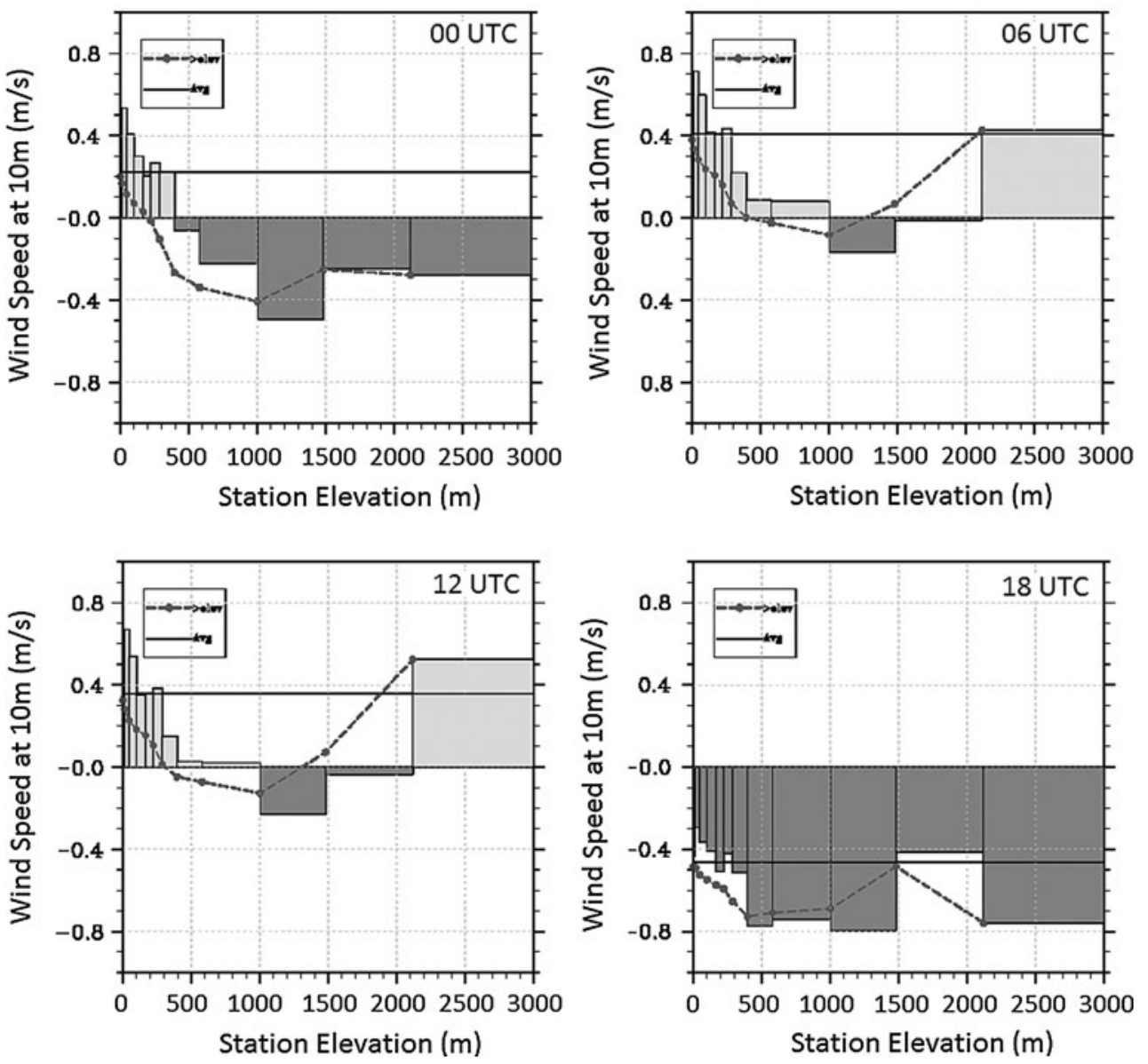

provides an exceptionally useful forecast dataset for studying the error properties of the WRF model forecasts, in terms of a longer time period and a broader coverage of geographic regions than previously studied. This study analyzes the characteristics of the 2-m temperature and $10-\mathrm{m}$ wind forecast errors from the NCAR-AirDat operational CONUS-scale 4-km grid WRF-RTFDDA forecasting system between 2009 and 2010. The verification of 2-m temperature, 10-m wind speed, and wind-direction forecasts shows that the error varies greatly with seasons, diurnal cycles, forecast lead times, geographical locations, and elevations. Keeping in mind the diversity of all the possible conditions affecting the forecasts, we can summarize the most noticeable error features as follows:

- The domain-cycle-averaged RMSE and bias of temperature and wind speed generally grow with forecast length, and display strong diurnal patterns in each cycle. The mean RMSE errors of temperature grow during the daytime and peak in the late afternoon. In comparison, the diurnal variations in wind speed errors are less pronounced with smaller errors during the nighttime and early morning but larger errors during the daytime that peak around noon.
- Model biases exhibit large seasonal variability, with a general tendency of under-prediction of the amplitude of the surface temperature and strongly positive nighttime surface wind speed biases during the entire study period. The warm temperature biases occur mainly during the nighttime, while the negative wind-speed biases are generally observed during the spring and summertime afternoons.

- The geographical distribution analysis shows large negative wind-direction biases along the slopes of the Rocky Mountains and in the Central Valley of California, and positive biases in the eastern and northwestern coastal areas. The biases in wind direction are strongly negative (counterclockwise) over the Rocky Mountains. The spatial distributions of the temperature biases feature east-west variations with large cold biases in the mountainous areas of California and Washington Rocky Mountains, and the Appalachian Mountains.

- The terrain elevation and topographical effects are significant factors affecting the model biases. The systematic cold biases that are independent of diurnal cycles appear at the low elevations in the coastal areas. 
At higher elevations with terrain height in excess of $600 \mathrm{~m} \mathrm{ASL}$, the cold (warm) biases are seen only during the daytime (nighttime). The highest wind speed errors are found over high terrain (mostly negative biases) and near sea-level stations (mostly positive biases). The negative temperature biases exist at all elevations around noontime. At elevations between 1,000 and 2,100 m, negative wind-speed biases with variable amplitudes during different weather conditions and forecast duration are identified for each cycle. Wind-direction errors, largest in the Rocky and Appalachian mountain ranges and in the western coastal areas, display strong diurnal and spatial variations.

This paper is focused primarily on analysis of the characteristics of the model-forecast errors. The error features suggest that the model physical parameterization schemes and model dynamic formulations behave differently according to the time of the day, seasons, and geographical (topography and land uses) contrasts. Additional work is necessary to better understand and identify the sources of these errors to improve the model forecasts. It is our hope that the current study could help inform the end-users in assessing the level of forecast errors in their own use of the NWP system, and meanwhile, provide the model developers insight into the behavior of the model-forecast error dependency given the complex sets of parameterizations.

Acknowledgments The authors are very grateful to NCAR for the technical and computer support. The comments and suggestions provided by Jason Knievel and Karen Griggs are greatly appreciated. NCAR is sponsored by the National Science Foundation.

Open Access This article is distributed under the terms of the Creative Commons Attribution License which permits any use, distribution, and reproduction in any medium, provided the original author(s) and the source are credited.

\section{References}

Angevine WM (2005) An integrated turbulence scheme for boundary layers with shallow cumulus applied to pollutant transport. J Appl Meteorol 44:1436-1452

Angevine WM, Jiang H, Mauritsen T (2010) Performance of an eddy diffusivity mass flux scheme for shallow cumulus boundary layers. Mon Weather Rev 138:2895-2912

Barlage M, Chen F, Tewari M, Ikeda K, Gochis D, Dudhia J, Rasmussen R, Livneh B, Ek M, Mitchell K (2010) Noah landsurface model modifications to improve snowpack prediction in the Colorado Rocky Mountains. J Geophys Res 115:D22101. doi:10.1029/2009JD013470

Case JL, Manobianco J, Dianic AV, Wheeler MM, Harms DE, Parks CR (2002) Verification of high-resolution RAMS forecasts over east-central Florida during the 1999 and 2000 summer months. Weather Forecast 17:1133-1151

Case JL, Crosson WL, Kumar SV, Lapenta WM, Peters-Lidard CD (2008) Impacts of high-resolution land surface initialization on regional sensible weather forecasts from the WRF model. J Hydrometeorol 9:1249-1266. doi:10.1175/2008JHM990.1

Chen F, Warner TT, Manning K (2001) Sensitivity of orographic moist convection to landscape variability: a study of the Buffalo Creek, Colorado, flash flood case of 1996. J Atmos Sci 58:32043223

Cheng WYY, Steenburgh WJ (2005) Evaluation of surface sensible weather forecasts by the WRF and the eta models over the Western United States. Weather Forecast 20:812-821

Childs, P, Jacobs N, Croke M, Huffman A, Liu Y, Wu W, Roux G, Ge M (2010) An introduction to the NCAR-AirDat operational TAMDAR-enhanced RTFDDA WRF-ARW. In: 14th Symposium on Integrated Observing and Assimilation Systems for Atmosphere, Oceans, and Land Surface (IOAS-AOLS), Jan 17-23 2010, Atlanta, Paper 8.4

Coleman RF, Drake JF, McAtee MD, Belsma LO (2010) Anthropogenic moisture effects on WRF summertime surface temperature and mixing ratio forecast skill in Southern California. Weather Forecast 25:1522-1535

Croke M, Jacobs NA, Childs P, Huffman A, Liu Y, Liu Y, Sheu R-S (2010) Preliminary verification of the NCAR-Airdat operational RTFDDA-WRF system. In: 14th Symposium on Integrated Observing and Assimilation Systems for the Atmosphere, Oceans, and Land Surface (IOAS-AOLS), AMS, 17-23 Jan 2010, Atlanta, Paper 8.5

Fritsch JM Jr, Houze RA, Adler R, Bluestein H, Bosart L, Brown J, Carr F, Davis C, Johnson RH, Junker N, Kuo Y-H, Rutledge S, Smith J, Toth Z, Wilson JW, Zipser E, Zrnic D (1998) Quantitative precipitation forecasting: report of the eight prospectus team, US weather research program. BAMS 79:285299

Garvert MF, Colle BA, Mass CF (2005a) The 13-14 December 2001 IMPROVE-2 event. Part I: synoptic and mesoscale evolution and comparison with a mesoscale model simulation. J Atmos Sci 62:3474-3492

Garvert MF, Woods CP, Colle BA, Mass CF, Hobbs PV, Stoelinga MT, Wolfe JB (2005b) The 13-14 December 2001 IMPROVE-2 event. Part II: comparisons of MM5 model simulations of clouds and precipitation observations. J Atmos Sci 62:3520-3534

Grell G, Dudhia J, Stauffer DR (1994) A description of the fifthgeneration Penn State/NCAR mesoscale model (MM5). NCAR Tech. Note NCAR/TN-398 + STR, National Center for Atmospheric Research, p 117

Hahn RS, Mass CF (2009) The impact of positive-definite moisture advection and low-level moisture flux bias over orography. Mon Weather Rev 137:3055-3071

Holt TR, Niyogi D, Chen F, Manning K, LeMone MA, Qureshi A (2006) Effect of land-atmosphere interactions on the IHOP 24-25 May 2002 convection case. Mon Weather Rev 134:113133

Jiménez PA, Dudhia J (2012) Improving the representation of resolved and unresolved topographic effects on surface wind in the WRF model. J Appl Meteor Climatol 51:300-316

Jiménez PA, Dudhia J (2013) On the ability of the WRF model to reproduce the surface wind direction over complex. J Appl Meteor Climatol. doi:10.1175/JAMC-D-12-0266.1

Jolliffe IT, Stephenson DB (2011) Forecast verification: a practitioner's guide in atmospheric science. Wiley, London, p 292

Jones MS, Colle BA, Tongue JS (2007) Evaluation of a mesoscale short-range ensemble forecast system over the Northeast United States. Weather Forecast 22:36-55

Lin Y, Colle BA (2009) The 4-5 December 2001 IMPROVE-2 event: observed Microphysics and comparisons with the weather research and forecasting model. Mon Weather Rev 137:13721392 
Lin Y, Colle BA (2011) A new bulk microphysical scheme that includes riming intensity and temperature-dependent ice characteristics. Mon Weather Rev 139:1013-1035

Lin YL, Farley RD, Orville HD (1983) Bulk parameterization of the snow field in a cloud model. J Clim Appl Meteor 22:1065-1092

Liu Y, Chen F, Warner T, Basara J (2006) Verification of a mesoscale data-assimilation and forecasting system for the Oklahoma City area during the joint Urban 2003 field project. J Appl Meteor Climatol 45:912-929

Liu Y, Jacobs NA, Yu W, Warner TT, Swerdlin SP, Anderson M (2007) An OSSE study of TAMDAR data impact on mesoscale data assimilation and prediction. In: 11th Symposium on Integrated Observing and Assimilation Systems for Atmosphere, Oceans, and Land Surface (IOAS-AOLS), AMS, 14-18 Jan 2007, San Antonio

Liu Y, Warner TT, Bowers JF, Carson LP, Chen F, Clough CA, Davis CA, Egeland $\mathrm{CH}$, Halvorson SF Jr, Huck TW, Lachapelle L, Malone RE, Rife DL, Sheu R-S, Swerdlin SP, Weingarten DS (2008a) The operational mesogamma-scale analysis and forecast system of the US Army test and evaluation command. Part I: overview of the modeling system, the forecast products, and how the products are used. J Appl Meteor Climatol 47:1077-1092

Liu Y, Warner TT, Astling EG, Bowers JF, Davis CA, Halvorson SF, Rife DL, Sheu R-S, Swerdlin SP, Xu M (2008b) The operational mesogamma-scale analysis and forecast system of the US Army test and evaluation command. Part II: interrange comparison of the accuracy of model analyses and forecasts. J Appl Meteor Climatol 47:1093-1104

Liu Y, Warner T, Wu W, Roux G, Cheng W, Liu Y, Chen F, Delle Monache L, Mahoney W, Swerdlin S (2009) A versatile WRF and MM5-based weather analysis and forecasting system for supporting wind energy prediction. In: 23rd WAF $/ 19^{\text {th }}$ NWP Conference, AMS, Omaha, NE. 1-5 June 2009, Paper 17B.3

Liu Y, Zhang Y, Wu W, Roux G, Ge M, Sheu R-S, Warner T, Jocobs N, Childs P, Croke M (2010) Evaluation of TAMDAR data impact on predicting warm-season convection using the NCARAirDat WRF-based RTFDDA system. In: 14th integrated observing and assimilation systems for the atmosphere, oceans and land surface (IOAS-AOLS), AMS, Atlanta, GA, 17-23 Jan 2010

Mass CF Ovens D (2013) Strange linear features in WRF clouds and precipitation: diagnosis and correction. In: 14th Annual WRF Users' Workshop, 24-27 June, Boulder, CO. Paper 8.2. http:// www.mmm.ucar.edu/wrf/users/workshops/WS2013/ppts/8.2.pdf

Mass CF, Ovens D (2011) Fixing WRF's high speed wind bias: a new subgrid scale drag parameterization and the role of detailed verification. In: 24th Conference on Weather and Forecasting and 20th Conference on Numerical Weather Prediction, Preprints, 91st American Meteorological Society Annual Meeting, 23-27 Jan, Seattle, WA. Paper 9B.6. http://ams.confex.com/ams/ 91Annual/webprogram/Paper180011.html

Milbrandt JA, Yau MK, Mailhot J, Bélair S (2008) Simulation of an orographic precipitation event during IMPROVE-2. Part I: evaluation of the control run using a triple-moment bulk microphysics scheme. Mon Weather Rev 136:3873-3893

Molders N (2008) Suitability of the weather research and forecasting (WRF) model to predict the June 2005 fire weather for Interior Alaska. Weather Forecast 23:953-973
Morrison H, Thompson G, Tatarskii V (2009) Impact of cloud microphysics on the development of trailing stratiform precipitation in a simulated squall line: comparison of one and twomoment schemes. Mon Weather Rev 137:991-1006

Prabha T, Hoogenboom G (2008) Evaluation of the weather research and forecasting model for two frost events. Comput Electron Agric 64(2):234-247

Rife DL, Warner TT, Chen F, Astling EA (2002) Mechanisms for diurnal boundary-layer circulations in the Great Basin Desert. Mon Weather Rev 130:921-938

Rife DL, Davis CA, Liu Y, Warner TT (2004) Predictability of lowlevel winds by mesoscale meteorological models. Mon Weather Rev 132:2553-2569

Romine GS, Schwartz CS, Snyder C, Anderson JL, Weisman ML (2013) Model bias in a continuously cycled assimilation system and its influence on convection-permitting forecasts. Mon Weather Rev 141:1263-1284

Rostkier-Edelstein D, Hacker JP (2010) The roles of surfaceobservation ensemble assimilation and model complexity for nowcasting of PBL profiles: a factor separation analysis. Weather Forecast 25:1670-1690

Rostkier-Edelstein D, Hacker JP (2013) Impact of flow dependence, column covariance, and forecast model type on surface-observation assimilation for probabilistic PBL profile nowcasts. Weather Forecast 28:29-54

Roux G, Liu Y, Delle Monache L, Sheu R-S, Warner TT (2009) Verification of high resolution WRF RTFDDA surface forecasts over mountains and plains. In: 10th WRF users' workshop, 20-23 June, 2009, Boulder

Sharman RD, Liu Y, Sheu R-S, Warner TT, Rife DL, Bowers JF, Clough CA, Ellison EE (2008) The Operational mesogammascale analysis and forecast system of the US Army test and evaluation command. Part III: forecasting with secondaryapplications models. J Appl Meteor Climatol 47:1105-1122

Skamarock WC, Klemp JB, Dudhia J, Gill DO, Barker DM, Wang W, Powers JG (2005) A description of the advanced research WRF Version 2. NCAR Technical Note, NCAR/TN-468 + (STR), National Center for Atmospheric Research, Boulder, p 88

Steeneveld GJ, Holtslag AAM, Nappo CJ, van de Wiel BJH, Mahrt L (2008) Exploring the possible role of small-scale terrain drag on stable boundary layers over land. J Appl Meteor Climatol 47:2518-2530

Steeneveld GJ, Nappo CJ, Holtslag AAM (2009) Estimation of orographically induced wave drag in the stable boundary layer during the CASES-99 experimental campaign. Acta Geophys $57: 857-881$

Sutton C, Hamill TM, Warner TT (2006) Will perturbing soil moisture improve warm-season ensemble forecasts? A proof of concept. Mon Weather Rev 134:3174-3189

Woods CP, Stoelinga MT, Locatelli JD (2007) The IMPROVE-1 storm of 1-2 February 2001. Part III: sensitivity of a mesoscale model simulation to the representation of snow particle types and testing of a bulk microphysical scheme with snow habit prediction. J Atmos Sci 64:3927-3948

Xu J, Rugg S, Byerle L, Liu Y (2009) Weather forecasts by the WRFARW model with the GSI data assimilation system in the complex terrain areas of Southwest Asia. Weather Forecast 24:987-1008 